\title{
Population genetics of the wolverine in Finland: the road to recovery?
}

\author{
Gerhardus M. J. Lansink ${ }^{1}\left(\mathbb{D} \cdot\right.$ Rodrigo Esparza-Salas $^{2}$ (D) Maija Joensuu $^{3} \cdot$ Anni Koskela $^{4} \cdot$ Dominika Bujnáková $^{1}(\mathbb{D}$.

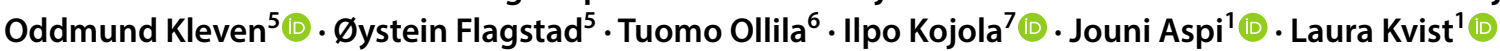

Received: 3 October 2019 / Accepted: 5 March 2020 / Published online: 13 March 2020

(c) The Author(s) 2020

\begin{abstract}
After decades, even centuries of persecution, large carnivore populations are widely recovering in Europe. Considering the recent recovery of the wolverine (Gulo gulo) in Finland, our aim was to evaluate genetic variation using 14 microsatellites and mtDNA control region (579 bp) in order (1) to determine whether the species is represented by a single genetic population within Finland, (2) to quantify the genetic diversity, and (3) to estimate the effective population size. We found two major genetic clusters divided between eastern and northern Finland based on microsatellites $\left(F_{S T}=0.100\right)$ but also a significant pattern of isolation by distance. Wolverines in western Finland had a genetic signature similar to the northern cluster, which can be explained by former translocations of wolverines from northern to western Finland. For both main clusters, most estimates of the effective population size $N_{e}$ were below 50. Nevertheless, the genetic diversity was higher in the eastern cluster $\left(H_{E}=0.57, A_{R}=4.0, A_{P}=0.3\right)$ than in the northern cluster $\left(H_{E}=0.49, A_{R}=3.7, A_{P}=0.1\right)$. Migration between the clusters was low. Two mtDNA haplotypes were found: one common and identical to Scandinavian wolverines; the other rare and not previously detected. The rare haplotype was more prominent in the eastern genetic cluster. Combining all available data, we infer that the genetic population structure within Finland is shaped by a recent bottleneck, isolation by distance, human-aided translocations and postglacial recolonization routes.
\end{abstract}

Keywords Conservation genetics · Gulo gulo $\cdot$ Microsatellites $\cdot$ MtDNA $\cdot$ Genetic structure $\cdot$ Genetic diversity

\section{Introduction}

Electronic supplementary material The online version of this article (https://doi.org/10.1007/s10592-020-01264-8) contains supplementary material, which is available to authorized users.

Gerhardus M. J. Lansink gerhardus.lansink@oulu.fi

1 Department of Ecology and Genetics, University of Oulu, P.O. Box 3000, 90014 Oulu, Finland

2 Department of Bioinformatics and Genetics, Swedish Museum of Natural History, P.O. Box 50007, 10405 Stockholm, Sweden

3 Kenttätie 10 B 21, 90130 Oulu, Finland

4 Metsähallitus, Parks and Wildlife Finland, P.O. Box 81, 90101 Oulu, Finland

5 Norwegian Institute for Nature Research, P.O. Box 5685, Torgarden, 7485 Trondheim, Norway

6 Metsähallitus, Parks and Wildlife Finland, P.O. Box 8016, 96101 Rovaniemi, Finland

7 Natural Resources Institute Finland (Luke), P.O. Box 16, 96301 Rovaniemi, Finland
Conservation of large carnivores represents a challenging issue especially due to the conflicts arising from their interaction with human activities. Large carnivores have suffered from considerable declines globally (Prugh et al. 2009; Ripple et al. 2014), but recent conservation efforts have aided the recovery of several populations in Europe (Chapron et al. 2014). Nevertheless, with extensive home range requirements and natural low densities, large carnivores are particularly sensitive to habitat fragmentation and limited connectivity between the patches (Crooks 2002; Crooks et al. 2011). Isolation can result in a fragmented genetic population structure, a decline of genetic diversity and increased inbreeding, followed by a decrease in reproductive potential and survival of the population (Frankham et al. 2010). Thus, assessing the genetic status is an important objective in predicting the sustainability of large carnivore populations (Frankham 2005).

To that end, non-invasive genetic sampling (e.g. using scats, hair or urine samples as a source of DNA) has proven 
an excellent method to measure the genetic status in wild populations of large carnivores (Lamb et al. 2019). The wolverine (Gulo gulo), one of the four large carnivores in northern Europe, is a characteristically scarce and elusive species (May et al. 2006, 2012; Persson et al. 2010; Inman et al. 2012; Fisher et al. 2013; Mykrä and Pohja-Mykrä 2015). Studies on wolverines in the wild are difficult to carry out due to their low population densities and the remoteness and harshness of their habitats (May et al. 2006; Persson et al. 2010). Therefore, development of non-invasive DNAtechniques provides an efficient way to learn more about this species (Hedmark et al. 2004, 2007; Brøseth et al. 2010; Magoun et al. 2011; Bischof et al. 2016; Gervasi et al. 2016).

Wolverines are found throughout the northern Holarctic with the European range in northwest Russia, Finland, Sweden and Norway (Fig. 1). Typical wolverine habitats in
Europe include alpine heaths and meadows, boreal forests, and mires (Landa et al. 2000; May et al. 2010; Koskela et al. 2013; Aronsson and Persson 2017; Hyvärinen et al. 2019). Approximately 300 to 500 wolverines were roaming in Finland at the beginning of the 1900s (Mykrä and Pohja-Mykrä 2015). During the twentieth century, their numbers severely declined due to human persecution. The decline continued through the 1970 and 1980s, when the breeding population was been decimated and wolverines were rarely observed except around the eastern and northern border of Finland (Fig. 2). Although at least 22 den sites were active in north-eastern Finland during the 1960s (Pulliainen 1968), the fatal combination of governmental bounties for killing and the increased use of snowmobiles in the hunt culminated in only two active dens in 1973 being located (Pulliainen and Nyström 1974). However,
Fig. 1 The sampling sites of wolverine individuals used in this study $(N=247)$ and current wolverine distribution in Finland and Europe. The black dots represent the locations of individuals. Individuals from the same location are displaced around a central point that corresponds to original location. The yellow dashed line represents the division of individuals into predefined populations East and North, as based on the approximated past population division (see Fig. 2). The extent of the Finnish reindeer husbandry area is depicted with small dots. The main study regions are labelled. The inset shows the current range of wolverines in northern Europe (adopted from Abramov 2016; Danilov et al. 2018; Flagstad et al. 2018; Natural Resources Institute Finland 2018) including the three population strongholds (Boitani et al. 2015)

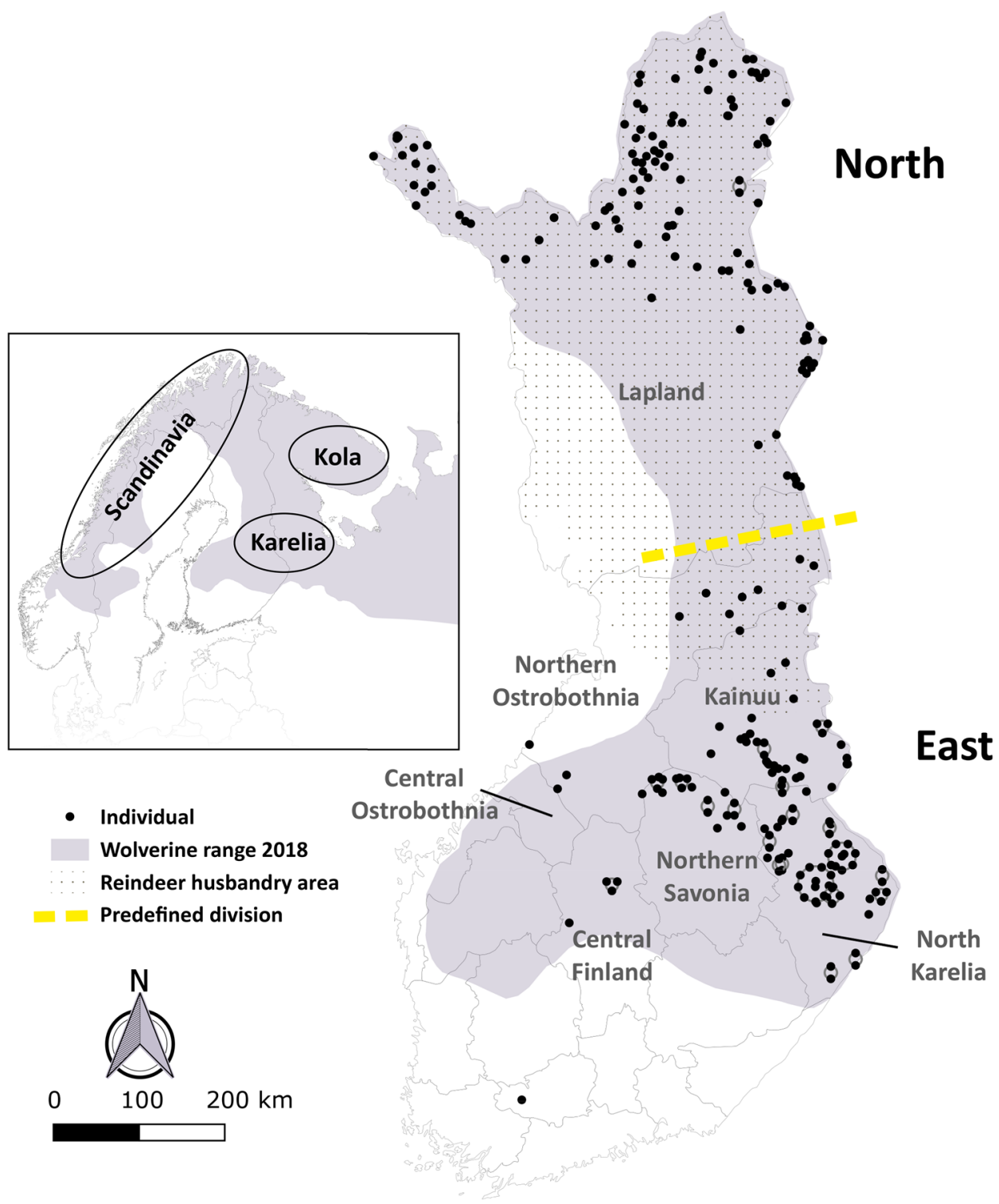




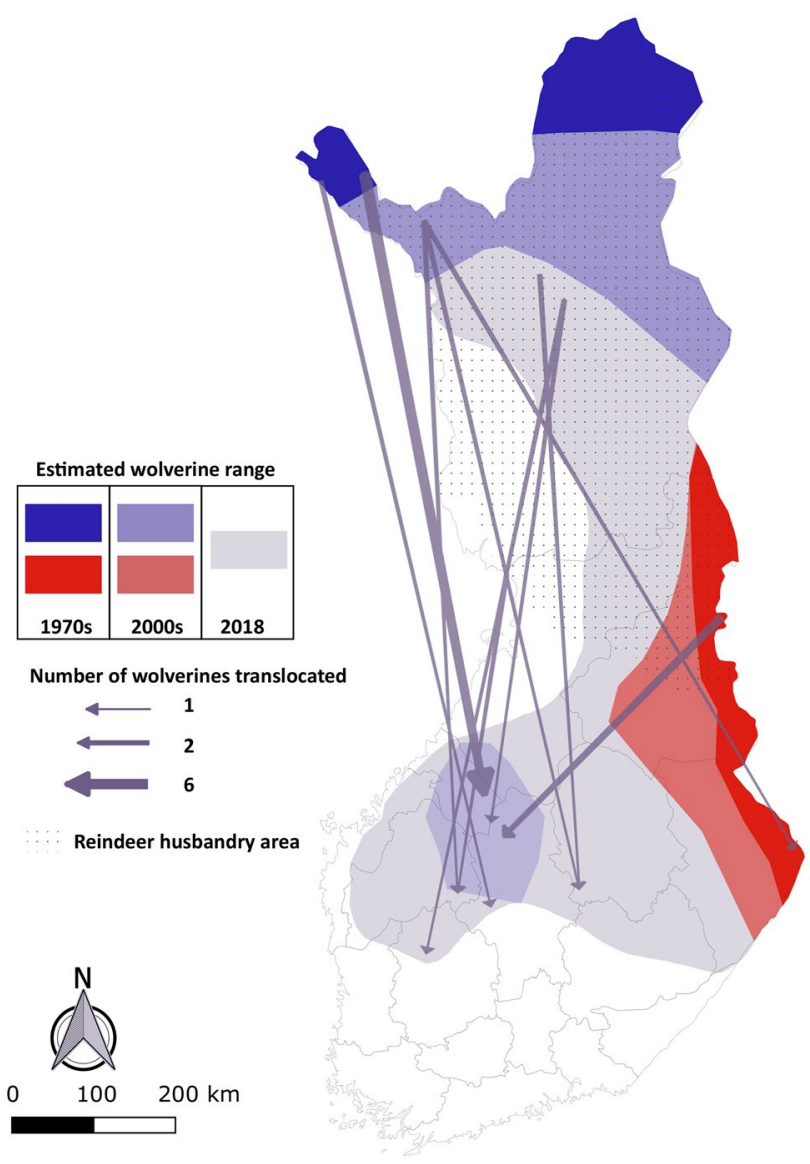

Fig. 2 Approximated increase of the breeding range of wolverines in Finland from 1970s to 2018. Hypothetical genetic clusters due to the bottleneck represented with blue (North and West) and red (East). The arrows represent 11 translocation events of 16 wolverines (10 males and 6 females) from 1979 to 1998 (Pohja-Mykrä and Kurki 2008). The two individuals translocated from eastern Finland were females. The thickest arrow represents two translocation events of three individuals each. The extent of the Finnish reindeer husbandry area is depicted with small dots. The historical Finnish wolverine ranges were based on Pulliainen and Nyström (1974), Landa et al. (2000) and Natural Resources Institute Finland (2018), while the current wolverine range was adopted from Abramov (2016) and Natural Resources Institute Finland (2018)

after wolverines became protected south of the reindeer husbandry area in 1978 and in the whole country in 1982, the population started to recover (Pohja-Mykrä and Kurki 2008). The reindeer husbandry area (Fig. 1), that covers $33 \%$ of Finland, is a region where people are practicing reindeer herding, and where the wolverine is considered the most harmful of all large carnivores to reindeer survival (Jernsletten and Klokov 2002). To promote the establishment of a larger breeding population outside the reindeer husbandry area (Pohja-Mykrä and Kurki 2008), 16 wolverines from northern Finland were translocated to 11 locations in western and central Finland during the 1980 and 1990s (Fig. 2).
During the last two decades, wolverine numbers have increased, especially outside the reindeer husbandry area in the boreal forests of Finland (Fig. 2) as likewise in Sweden (Aronsson and Persson 2017). Nevertheless, the recovery in Finland was initially slow, likely due to continued legal culling and poaching (Ermala 2003; Pohja-Mykrä and Kurki 2008). At present, the western periphery of the Eurasian wolverine range displays three population strongholds within northern Europe: one in Scandinavia, including areas of Norway, Sweden and northernmost Finland; one in Karelia, including Eastern Finland and neighbouring parts of Russian Karelia; and one on the Russian Kola Peninsula (Fig. 1) (Boitani et al. 2015). Using a combination of a count method (i.e. count of reproductive dens) and capture-recapture models (i.e. long-term non-invasive genetic sampling) (Gervasi et al. 2016), 300-350 individuals have been identified in Norway, 400-650 in Sweden and about 130 in northern Finland (Persson and Brøseth 2011; Boitani et al. 2015; Kojola 2018; Flagstad et al. 2018). Using only count-based methods (e.g. snow track data, sightings, droppings and carrions killed by wolverine), about 155 and 160 individuals have been estimated in Finnish and Russian Karelia, respectively (Danilov et al. 2018; Kojola 2018). A census population size estimate for the Kola Peninsula varies between 300 and 440 individuals (Boitani et al. 2015; Danilov et al. 2018).

Although genetic population structure of Scandinavian wolverines has been studied (Walker et al. 2001; Flagstad et al. 2004; Hedmark and Ellegren 2007; Ekblom et al. 2018), it has not been assessed in Finland. Based on both microsatellites and SNPs, the extant Scandinavian population appears to be subdivided into two clusters: south-western Norway and the rest of Scandinavia (Walker et al. 2001; Flagstad et al. 2004; Ekblom et al. 2018). On the other hand, no variation was found across Scandinavia in the mitochondrial whole genome (Ekblom et al. 2014) or in the control region of the mtDNA (Walker et al. 2001). The Scandinavian mtDNA haplotype (Arnason et al. 2007; Ekblom et al. 2014) was additionally present in north-east Russia and in Alberta, Canada (Tomasik and Cook 2005; Zigouris et al. 2013) (termed haplotype 15 sensu Zigouris et al. 2013). A recent genomic analysis of Scandinavian wolverines revealed low genetic diversity and an effective population size of below 500 individuals (Ekblom et al. 2018), which may be too low to retain evolutionary potential (Frankham et al. 2014).

Currently, the wolverine is globally listed by IUCN as Least Concern because of high population numbers in North America and Russia (Abramov 2016), while on a national scale, they are categorized as vulnerable in Sweden and Russian Karelia, and as endangered in Finland and Norway (Boitani et al. 2015; Henriksen and Hilmo 2015; Hyvärinen et al. 2019). Wolverines are, however, managed by quotabased hunting in Norway, whereas Sweden and Finland belong to the European Union and therefore, legal hunting 
is restricted (Gervasi et al. 2016). In Russian Karelia, the species is fully protected by law but illegally hunted for fur (Danilov et al. 2018).

In this study, we examine putatively neutral genetic variation (14 microsatellites and $579 \mathrm{bp}$ of control region mtDNA) of wolverines in Finland in order (1) to determine whether the species reflects a single genetic population within Finland, (2) to quantify genetic diversity, and (3) to estimate the effective population size. We expected to observe weak genetic population structure, as the species is well-known for its capability of long distance dispersal (Gardner et al. 1986; Vangen et al. 2001; Flagstad et al. 2004; Inman et al. 2012). On the other hand, genetic differentiation between eastern and northern Finland might have occurred during the documented bottleneck (Fig. 2), resulting in northern Finland being part of the Scandinavian population and eastern Finland as part of the Karelian population (Fig. 1) (Chapron et al. 2014; Boitani et al. 2015). In this scenario, due to the translocations, wolverines in western Finland would possibly be more similar to their northern conspecifics. Population subdivision due to a recent bottleneck has been proposed to explain population structure in brown bears (Ursus arctos) in Finland (Kopatz et al. 2014) and wolverines in Scandinavia (Walker et al. 2001; Flagstad et al. 2004). Genetic diversity and effective population size estimates of wolverine population(s) in south-eastern Finland are expected to be higher than on the edge of the Eurasian range (i.e. northern Finland as part of the Scandinavian populations) due to the assumed connectivity of the Karelian population with larger populations in north-western Russia.

\section{Material and methods}

\section{Sampling and molecular analyses}

We collected 1281 wolverine samples between the years 1983 and 2018 from northern, central and eastern Finland. Scat samples $(N=936)$ were collected as part of the Scandinavian population from Finnish Lapland and as part of the Karelian population from Northern Ostrobothnia, Kainuu and North Karelia since 2003. Hair samples $(N=296)$ were collected from 33 non-invasive snag sites in the regions of North Karelia, Northern Savonia, Central Finland, Kainuu and Northern Ostrobothnia (all from the Karelian population) since late 2015 (Detailed description in Supplement 1). We obtained an additional 43 tissue samples from wolverine individuals found dead or legally culled (during the 2017-2018 winter season), independent of our research. Most of the tissue samples were from 1999 onwards, except for three museum samples $(1983 N=01 ; 1991 N=02)$. Additional museum samples $(N=05)$ consisted of blood on
FTA cards (GE Healthcare, UK) (2006-2007) and a tooth (1995).

\section{Microsatellites, PCR amplification and quality control}

Details covering the laboratory protocols of DNA extraction and microsatellite genotyping are provided in Supplement 1 . Briefly, 14 microsatellite markers were grouped in 2 multiplex sets for amplification (7 in each; Table S1). In addition, two mustelid-specific Y-chromosome-linked loci were included to the first multiplex group for sex determination (Hedmark et al. 2004). Non-invasive samples were replicated at least three times and tissue samples twice to check for consistency between scores. A single locus was scored as a heterozygote, when a clear heterozygous profile among replicates could be identified while other replicates showed up as homozygotes (i.e. allelic dropout). If scoring of a single locus varied inconsistently (i.e. shifting), it was marked as missing.

To verify the uniqueness of each genotype, an identity analysis implemented in the program CERVUS v.3.0.7 (Kalinowski et al. 2007) was used. Genotypes were considered to belong to the same individual if at least 12 out of 14 loci were matching (i.e. 2 mismatches between genotypes were allowed to account for possible genotyping errors) and were of the same sex. Probability of identity for unrelated individuals (PI) and probability of identity for siblings $\left(\mathrm{PI}_{\text {sibs }}\right)$ among all individuals, estimated with CERVUS, were $3.69 \times 10^{-9}$ and $1.45 \times 10^{-4}$ (Waits et al. 2001), respectively. To check for genotyping error, program MICROCHECKER v. 2.2.3 (Van Oosterhout et al. 2004) was used with a Bonferroni-adjusted $95 \%$ confidence interval and 1000 iterations. Individuals from the predefined Karelian and Scandinavian populations (Boitani et al. 2015), hereafter called East and North, were analysed both separately and by grouping them together. Additionally, rates of allelic dropout and false alleles across PCRs were estimated following Broquet and Petit (2004).

\section{Mitochondrial DNA}

A 579 bp fragment of the mitochondrial DNA (mtDNA) control region was amplified from 129 individuals using primers GuloF (Schwartz et al. 2007) and GuloR (5'-CACCTT ATGGTTGTGCGATG-3'; this study). Successfully amplified PCR products were purified using the EXOI/FastAPmethod (Thermo Scientific, Lithuania) and sequenced using BigDye Terminator v3.1 (Applied Biosystems, Foster City, California, USA). The haplotype sequences are available in GenBank with Accession Numbers MN854422-MN854423. More details covering the mtDNA sequencing are provided in Supplement 1. 


\section{Population genetic analyses}

GENEPOP v.4.2 (Rousset 2008) was used to test for deviations from Hardy-Weinberg equilibrium across all loci in both predefined populations and to detect potential linkage disequilibrium between pairs of loci within populations. It is well-known that variation within populations can be explained by isolation-by-distance (IBD; Wright 1943), which was tested in SPAGEDI v. 1.5 (Hardy and Vekemans 2002), correlating spatial distances and pairwise relatedness among all individuals. We used the kinship coefficient estimator described in Loiselle et al. (1995), which is suitable in cases when low frequency alleles are present in the data (Hardy and Vekemans 2002). A distance interval was set using the equal frequency method to 10 spatial distance classes. The kinship coefficient for each distance class and the overall regression slope were run with 10,000 permutations. Jackknifing over loci was applied to estimate standard errors to multilocus average estimates. Additionally, IBD was tested with a Mantel test (Mantel 1967; Diniz-Filho et al. 2013) on genetic and geographical distances of all individuals using GENALEX 6.5 (Peakall and Smouse 2012).

The population structure of Finnish wolverines was examined with the Bayesian clustering method implemented in STRUCTURE v.2.3.4 (Pritchard et al. 2000). The program estimates the likelihood for a given number of genetic clusters $(K)$ in the data and assigns the individuals to the defined clusters. A number of $K$ from 1 to 8 (10 iterations each) was tested under the admixture model with correlated allele frequencies (Falush et al. 2003) and run settings varying from 100,000 to 250,000 as burn-in and 250,000 to 500,000 Markov Chain Monte Carlo (MCMC) replication steps. Alpha, the parameter that implies admixture, was inferred from the data, initially set to 1.0. No prior information was used about sampling locations. Optimal $K$ was estimated using the $\Delta K$ method (Evanno et al. 2005) and by plotting the likelihood of $K$ for each value of $K(\operatorname{Ln} \operatorname{Pr}[\mathrm{X} \mid \mathrm{K}])$ (Pritchard et al. 2000) using the POPHELPER web app (Francis 2017). Additionally, we used the median of medians, median of means, maximum of medians, and maximum of means implemented in STRUCTURESELECTOR ( $\mathrm{Li}$ and Liu 2018) to account for uneven sampling (Puechmaille 2016). Assignment results were visualized with CLUMPAK (Kopelman et al. 2015). Individuals were assigned to a cluster when the membership coefficient (hereafter $q$ ) $>0.8$. Subsequent rounds of analysis followed identical settings but using a location prior based on the predefined regions (East and North), a hierarchical STRUCTURE analysis (Vähä et al. 2007) or sex-specific population structure. In the hierarchical analysis, individuals assigned to a cluster with $q<0.5$ were discarded after each round of the analysis. Further, to infer if genetic structure could be explained by an underlying family structure, a maximum likelihood model in COLONY (Jones and Wang 2010) was used.

Genetic population structure was additionally examined with GENEPLOT (McMillan and Fewster 2017). GENEPLOT applies the saddlepoint method (McMillan and Fewster 2017), which allows plotting genetic structure with quantile lines for each population. The analysis, using the a priori information of the predefined regions (East and North), was applied with the "leave-one-out" method (McMillan and Fewster 2017) and the prior as defined Rannala and Mountain (1997). Individuals were subsequently classified based on the GENEPLOT quantiles as East, North, Admixed or Outgroup.

An alternative approach to Bayesian clustering methods in the form of a discriminant analysis of principal components (DAPC) was used to assess the presence of major patterns in the multivariate data implemented in the package ADEGENET 2.1.1. (Jombart 2008; Jombart and Ahmed 2011) in R (R Core Team 2017). All principal components (PCs, 40) were used to determine the number of clusters maximizing the variation between clusters using the predefined populations. The find.clusters function was used to select the optimal number of clusters based on BIC scores with $10^{6}$ iterations. We used cross validation to calculate the number of retained PCs (20) with the xvalDapc function.

Individuals were spatially projected with QGIS 2.18 .16 (QGIS Development Team 2018). Current core population areas (CCPA; e.g. Tammeleht et al. 2010; Silva et al. 2018) were produced by computing minimum convex hulls around individuals with high membership values $(q>0.8)$ based on most likely population clustering while excluding migrants. If CCPAs were overlapping, the presence of males with very high membership values $(q>0.95)$ or females with high membership values $(q>0.8)$ was assumed as sufficient to include the area. Eight individuals were included twice (six in CCPA East; two in CCPA North). If CCPAs were bordering at a location where individuals were assigned to different clusters, males with very high membership values $(q>0.95)$ or females with high membership values $(q>0.8)$ were grouped into a cluster of assignment. A total of three individuals did not assign to any CCPA and were discarded from the following genetic analysis.

For every CCPA, we estimated the mean membership values and the proportion of assigned individuals versus admixed individuals for $K=2$, the family group structure and signs of recent migration. Every individual that was assigned by STRUCTURE, GENEPLOT or GENECLASS 2 (Piry et al. 2004) to another CCPA than the CCPA where the individual was originally found in, except where CCPAs overlapped, was considered as a recent migrant. GENECLASS 2 was used with the partially Bayesian assignment criteria of Rannala and Mountain (1997) and the Monte-Carlo resampling algorithm of Paetkau et al. (2004) (10,000 replicates; 
significance level at $\mathrm{P} \leq 0.01$ ) to assess the probability of being a first-generation migrant. These three programs were used to account for the different assumptions used in each of them (Berry et al. 2004). The distance of possible migrants to the cluster of assignment was measured ( $\mathrm{km}$, Euclidean distance to border) to reveal dispersal distances from their cluster of assignment.

We tested if stepwise mutations contributed to genetic differentiation by using 10,000 allele size permutations in SPAGEDI. As the allele size permutation test showed no significant contribution of stepwise mutations $(P=0.82)$ to the genetic structure, population differentiation was measured by allelic identity $\left(F_{S T}\right)$. Differentiation between CCPAs was measured for microsatellites by $F_{S T}$ with a locus-bylocus analysis of molecular variance (AMOVA). $F_{S T}$ values were analysed for significance with 10,000 permutations in ARLEQUIN v.3.5.2.2 (Excoffier and Lischer 2010).

Genetic diversity was measured for each CCPA in ARLEQUIN by estimating the number of alleles $(A)$, the observed $\left(H_{O}\right)$ and expected heterozygosities $\left(H_{E}\right)$ for all loci. Genetic diversity estimates were compared between the CCPAs using FSTAT v2.9.4. (Goudet 2003) with 10,000 permutations. Inbreeding coefficients $\left(F_{I S}\right)$ were estimated using allele identity in GENEPOP. Population-specific $F_{I S}$ indices were tested for significance using 10,000 permutations in ARLEQUIN. Allelic richness $\left(A_{R}\right)$ and private allelic richness $\left(A_{P}\right)$ were estimated for all loci using HP-RARE v. 6-2006 (Kalinowski 2005) with an adjusted sample size according to lowest number of genes. Private alleles were identified using GENALEX.

To disentangle the effect of population admixture and IBD on population structure, we divided the CCPAs by equal distance $(150 \mathrm{~km})$ from the supposed contact zone (Fig. S2). A similar analysis of genetic diversity as before was applied on individuals in each buffer, including the number of linked markers. CCPA North was divided in three buffer zones, whereas CCPA East was divided in four zones. CCPA West was excluded from this analysis.

Contemporary effective population size $\left(N_{e}\right)$ was estimated for each CCPA using the linkage disequilibrium (Hill 1981; Waples 2006; Waples and Do 2010), molecular coancestry (Nomura 2008) and temporal methods (Nei and Tajima 1981; Pollak 1983; Jorde and Ryman 2007) in NeESTIMATOR v.2.1 (Do et al. 2014). These several independent methods were used, as $N_{e}$ estimates seem to be sensitive to assumptions of different models (Wang et al. 2016). Notice that estimates given by these methods reflect actually the effective number of breeders $N_{e b}$, which do not always accurately resemble the $N_{e}$ (Nomura 2008). The $N_{e}$ estimate represents the number of breeders in the entire population. Rare alleles, with a frequency less than $2 \%$, were excluded $\left(P_{C r i t}=0.02\right.$; see Waples and Do 2010), except for the molecular coancestry method, where rare alleles should not bias the results (Do et al. 2014). For the linkage disequilibrium model, the mean from the estimates of monogamous and random mating was calculated. This was done because wolverines in Fennoscandia exhibit a polygamous mating structure, where male territories overlap several female territories (Hedmark et al. 2007), and thus neither of the mating systems implemented in NeESTIMATOR fits perfectly. For the temporal model, each CCPA was divided into temporal clusters: the CCPA North-West in two clusters [2007-2012 $(N=47), 2013-2018(N=63)]$ and the CCPA East in three clusters [2001-2006 $(N=19)$, 2007-2012 $(N=23), 2013-2018(N=26)]$. Generation time was approximated as 6 years (Rauset et al. 2015). To equalize the sample size for CCPA East, six individuals were randomly chosen to represent the years 2016-2017. Temporal methods, which were chosen because most of the samples were non-invasively collected (Do et al. 2014), were used with a conservative starting census size $N_{c}$ of 800 individuals for CCPA North-West and 1500 individuals for CCPA East, assuming connectedness towards the entire population of wolverines in the Russian part of Europe (Landa et al. 2000; Boitani et al. 2015).

We tested for recent genetic bottlenecks for the whole population and for each CCPA separately using the heterozygosity excess method implemented in BOTTLENECK (Piry et al. 1999). We applied the two-phase model (TPM; Di Rienzo et al. 1994) with variance in TPM $=30$ and proportion of stepwise mutations in TPM $=70 \%$ and used 10,000 iterations. In addition, we calculated the ratios of numbers of microsatellite alleles to their size range (i.e. Garza-Williamson indices 2001) implemented in ARLEQUIN.

Mitochondrial sequences were manually edited and aligned with available GenBank wolverine mtDNA sequences (Wilson et al. 2000; Walker et al. 2001; Tomasik and Cook 2005; Arnason et al. 2007; Schwartz et al. 2007; Frances 2008; Ekblom et al. 2014; Zigouris et al. 2013; Malyarchuk et al. 2015) using the ClustalW algorithm (Thompson et al. 1994) in MEGA 7 (Kumar et al. 2016). Haplotype $(\hat{h})$ and nucleotide $(\pi)$ diversities were calculated with DnaSP 5 (Librado and Rozas 2009). A median-joining haplotype network was drawn using NETWORK v.4.6.1.6 (Bandelt et al. 1999) with a shorter sequence of $317 \mathrm{bp}$ $(N=1033)$ to allow most of the previously published data to be compared with our data.

\section{Results}

Out of a total of 1281 putative wolverine samples, 56.5\% $(N=724)$ contained sufficient amounts of DNA for PCR amplification. We successfully genotyped $49.7 \%(N=465)$ of the scat and $70.9 \%(N=210)$ of the hair samples. A total of 247 wolverine individuals were identified from the 
predefined populations with 118 individuals from North and 129 from East (Fig. 1). The number of males and females in North was 51 and 67 and in East it was 71 and 53 (5 unknown), respectively. The longest time difference between recaptures was 8 years.

Evidence of null alleles was detected in five loci $(\mathrm{Gg} 454$, $\mathrm{Gg} 234, \mathrm{Gg} 14, \mathrm{Gg} 465$ and $\mathrm{Tt} 4$ ) and stuttering in three loci (Gg234, Gg14 and Tt4). However, these results were not consistent, when predefined populations were analysed separately (Table S2), which suggested the excess of homozygotes did not result from genotyping artefacts. Therefore, all loci were included in further analyses. The overall replicate error was small, $4.1 \%$ across all loci, largely caused by allelic dropout $(60.8 \%)$. We found a non-random allele association between one pair of microsatellite loci in both populations separately using a sequential Bonferroni correction: Gg454-Mvis057 ( $\mathrm{P}<0.001)$. The non-random association was likely caused by chance due to small population size and/or recent admixture and therefore both loci were retained. A significant pattern of IBD was found among Finnish wolverines $\left(b_{\text {loiselle }}=-0.043, r^{2}=0.137, P<0.001\right.$, Fig. S3; Mantel test: $\left.r^{2}=0.0673, P<0.001\right)$.

\section{Genetic structure}

Bayesian clustering assignment in STRUCTURE without prior information of sampling sites suggested two genetic clusters in the Finnish wolverine population based on $\Delta K$, but the posterior likelihood values were increasing until five clusters (Fig. S4). The four estimators suggested by Puechmaille (2016) supported two to four clusters (Fig. S5). Wolverines were divided geographically from eastern to northern Finland, except for the individuals from western Finland (main translocation site), which were assigned together with the northern individuals (Fig. 3a, b). The proportion of individuals assigned to clusters $(q>0.8)$ was high for $K=2$ (88.7\%) but less for $K=3(74.9 \%), K=4(63.2 \%)$ and $K=5$ (64.8\%). A temporal division of the optimal clusters did not reveal major cluster changes through time (Fig. S6). The addition of location information and performing a hierarchical analysis accentuated the same population structure with minimal differences from the general analysis (Figs. S7, S8). Also, the male and female population structure analysis showed a clear split of the population from east to north (Figs. S9, S10).

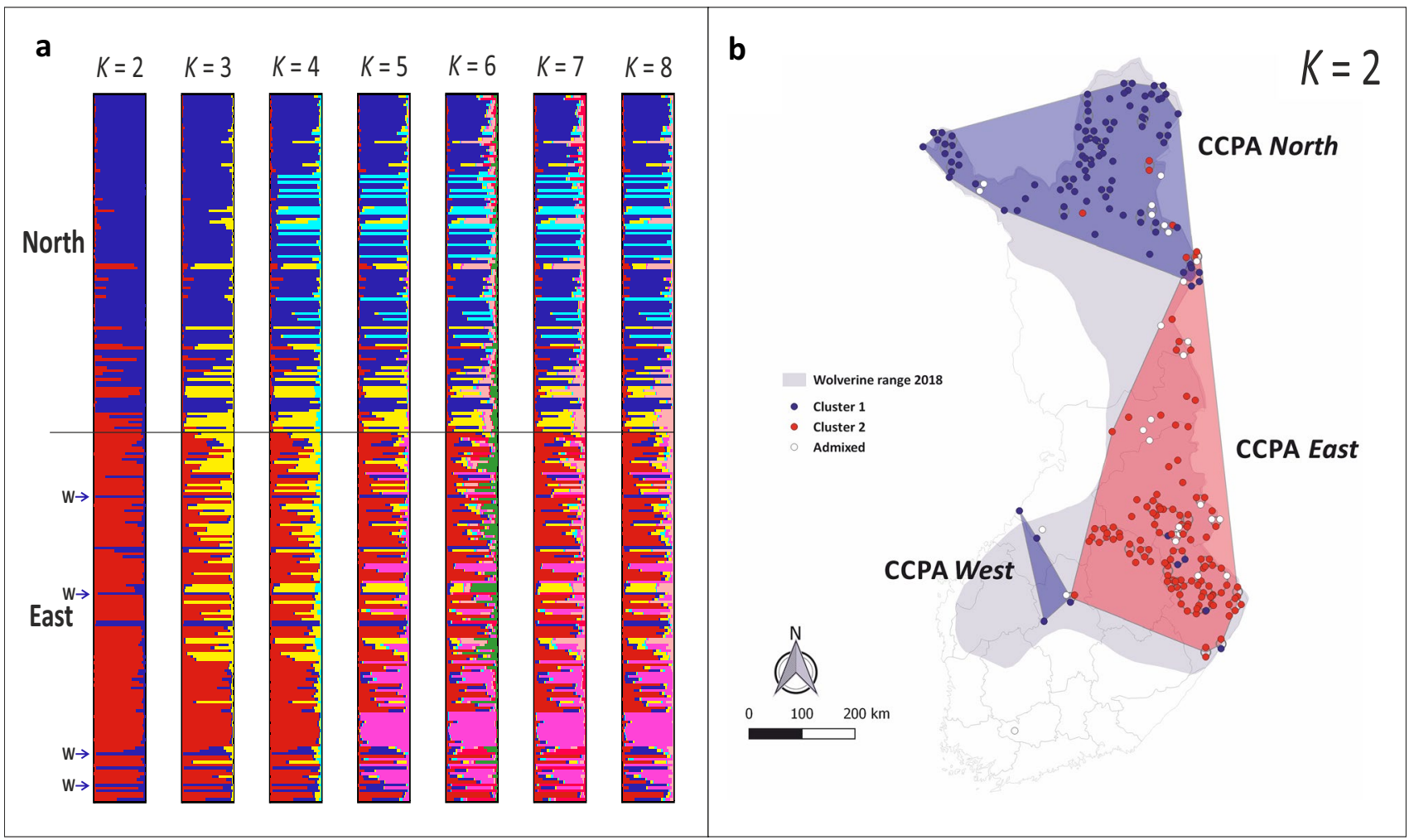

Fig. 3 Wolverine cluster assignment based on 14 microsatellites with STRUCTURE. a STRUCTURE assignment plots for runs until $K=8$ sorted by predefined populations North and East. Samples assigned to CCPA West are marked with a blue arrow and the letter $W$. b Spatial distribution of STRUCTURE results for $K=2$. Colours on the map correspond to individuals with membership value $q>0.8$. Admixed individuals with $q<0.8$ are depicted in white. Minimum convex hulls represent current core population areas (CCPAs) 
GENEPLOT showed a similar geographic division of population clusters as the general analysis in STRUCTU $\mathrm{RE}$, including the assignment of individuals from western Finland to the northern cluster (Fig. S11). Besides, a large proportion of the individuals were included to both populations. A few individuals, mainly from the most northern areas of the predefined East population, were not grouped to any cluster $(N=10)$. Interestingly, these outgroup individuals all belong to the third cluster recognized by STRUCTU $\mathrm{RE}$ at $K=3$ in the general analysis.

The values of Bayesian Information Criterion (BIC) in DAPC showed a decrease until reaching minimum values between 8 and 12 clusters, though showing a geographic separation from east to north on the first principal component axis (Fig. S12). The geographic clusters were, however, partially overlapping.

Analysis of family groups in COLONY revealed 25 groups of wolverines in Finland. Mean size of one family group was 6.56 ( $S D \pm 5.84$; range $1-28)$. Two family groups consisted exactly of those individuals that were assigned by STRUCTURE to the two fine-scale clusters at $K=5$. Increasing $K$ values after reaching $K=3$ was thus likely explained by family structure in the data.

Based on the above results, we divided the wolverines in three CCPAs: East $(N=138)$, North $(N=110)$ and West $(N=04)$ (Fig. 3). Although the sample size of CCPA West was small, we considered it as a separate cluster due to the geographical disconnectivity with CCPA North and the presence of females. CCPA East stretched along the eastern border of Finland around the core regions of North Karelia,
Northern Savonia, Kainuu and Northern Ostrobothnia into south-eastern Lapland. The CCPA North extended over northern Finnish Lapland. The CCPA West included regions of Central Finland, Central Ostrobothnia and southern parts of Northern Ostrobothnia.

The mean membership value for CCPA East was $q=0.84$. Within CCPA East $81.2 \%$ of the individuals were assigned to the eastern cluster, $7.2 \%$ to the northern cluster and $11.6 \%$ were admixed. CCPA North had a mean membership value of $q=0.88$ with $85.4 \%$ of the assignments to the northern cluster, $5.5 \%$ to the eastern cluster and $9.1 \%$ of admixed individuals. The mean membership value for CCPA West was $q=0.96$ with all individuals assigned to the northern cluster.

When family groups were compared between CCPAs, a clear distinction was found in their composition, which was reflected also when sexes were analysed separately (Fig. S13). In CCPA East, half of the individuals belonged to 4 family groups (total $=21$ family groups; average per group $=7$ individuals). In CCPA North, nearly three-quarters of the individuals belonged to only 6 family groups (total $=16$ family groups; average per group $=7$ individuals). In CCPA West, all four individuals belonged to a singlefamily group.

Four recent migrants were found in CCPA North with strong assignments to CCPA East (STRUCTURE $K=2$; Table 1). Comparably, using GENEPLOT one of these individuals was assigned as a recent migrant and GENECLASS 2 assigned two of these individuals as potential first generation migrants. Mean distance of all migrants from the border of CCPA East was $127 \mathrm{~km}$. Five recent migrants were

Table 1 Recent migrants detected with STRUCTURE ( $q>0.8$ marked in bold), GENEPLOT and GENECLASS 2 in CCPA North and East, except where CCPAs overlapped

\begin{tabular}{|c|c|c|c|c|c|c|c|c|}
\hline Individual & Location & $\begin{array}{l}\text { Distance to } \\
\text { border }(\mathrm{km})\end{array}$ & Sex & Year & $q($ North-West $)$ & $q($ East $)$ & GENEPLOT & GENECLASS \\
\hline \multicolumn{9}{|l|}{ North } \\
\hline Gg060 & Inari & 144 & M & 2011 & 0.1981 & 0.8019 & Admixed & \\
\hline Gg061 & Inari & 144 & M & 2011 & 0.1353 & 0.8647 & Admixed & \\
\hline Gg089 & Sodankylä & 165 & $\mathrm{~F}$ & 2009 & 0.0252 & 0.9748 & Admixed & $F_{0}$ Migrant \\
\hline Gg093 & Savukoski & 55 & $\mathrm{~F}$ & 2014 & 0.1545 & 0.8455 & East & $F_{0}$ Migrant \\
\hline \multicolumn{9}{|l|}{ East } \\
\hline Gg113 & Salla & $76 / 362$ & M & 1999 & 0.6929 & 0.3071 & North & \\
\hline Gg134 & Kuhmo & $335 / 267$ & $\mathrm{~F}$ & 2017 & 0.7805 & 0.2195 & North & \\
\hline Gg159 & Sotkamo & $382 / 201$ & $\mathrm{~F}$ & 2004 & 0.9890 & 0.0110 & North & $F_{0}$ Migrant \\
\hline $\mathrm{Gg} 185$ & Nurmes & $424 / 203$ & $\mathrm{~F}$ & 2007 & 0.9657 & 0.0343 & Admixed & \\
\hline $\mathrm{Gg} 186$ & Nurmes & $424 / 203$ & M & 2007 & 0.9745 & 0.0255 & Admixed & $F_{0}$ Migrant \\
\hline Gg236 & Joensuu & $510 / 233$ & M & 2017 & 0.9566 & 0.0434 & Admixed & \\
\hline Gg244 & Tohmajärvi & $579 / 272$ & M & 2017 & 0.9565 & 0.0435 & Admixed & \\
\hline
\end{tabular}

Euclidean distance to border is a distance of northern individuals to the border of CCPA East, and for eastern individuals to the border of CCPA North and CCPA West, respectively. The $q$ values are from STRUCTURE $K=2$. For the GENEPLOT assignments, see "Material and methods". The individuals detected with GENECLASS 2 are potential first generation migrants 
found in CCPA East with strong assignments to CCPA North (STRUCTURE $K=2$; Table 1). Using GENEPLOT, three migrants were assigned, one of these was the same as with STRUCTURE. GENECLASS 2 detected two potential first generation migrants in CCPA East, both were detected with STRUCTURE as well. The mean distance of migrants from the border of CCPA North was $390 \mathrm{~km}$ and from the border of CCPA West $249 \mathrm{~km}$.

The AMOVA analysis (CCPA West combined with North) showed that $9.97 \%$ of the variation was explained by variance among CCPAs $\left(F_{S T}=0.100,95 \% \mathrm{CI}=0.046-0.160\right.$, $\mathrm{P}<0.001)$, which was comparable but not as strong as the pairwise $F_{S T}$ of clusters from STRUCTURE at $K=2\left(F_{S T}=\right.$ $0.152,95 \% \mathrm{CI}=0.075-0.239, \mathrm{P}<0.001)$.

\section{Genetic diversity}

Estimates of genetic diversity for the CCPAs are summarized in Tables 2 and S3. The mean expected heterozygosity $\left(H_{E}\right)$ was higher in CCPA East than in CCPA North-West. Besides, CCPA East had a higher mean allelic richness $\left(A_{R}\right)$ and mean private allelic richness $\left(A_{P}\right)$ than CCPA NorthWest. Nevertheless, none of the differences in estimates of genetic diversity between the clusters were significant $(\mathrm{P}>0.345)$. Also, the mean inbreeding coefficients were low and not significant at the population level $(\mathrm{P}>0.387)$. There was no difference in genetic diversity within the CCPAs and within the clusters from STRUCTURE $(K=2$; Table S4). Four private alleles were exclusively found in CCPA East, though with low frequencies $(<0.011)$. Yet, private alleles were abundant considering the STRUCTU RE based clusters at $K=2$. Five private alleles were found in cluster 1 (i.e. northern; mean allele frequency $=0.068$ ), whereas 10 were unique to cluster 2 (i.e. eastern; mean allele frequency $=0.141)$. There were two private alleles characteristic (mean allele frequency $>0.1$ ) for cluster 1 (Mvis075: allele 142; Gg465: allele 183) and three (mean allele frequency > 0.3) for cluster 2 (Gg443: allele 90; Gg454: allele 135; Gg234: allele 96). No private alleles were found in CCPA West when tested apart from CCPA North. Increased allelic richness was observed in both CCPAs, closer to the contact zone, where the assignment probability was lower (Table 3). However, no clinal patterns were detected for $H_{E}$, $F_{I S}$ or for the number of linked markers.

\section{Effective population size}

Very low and similar estimates of current $N_{e}$ were found for both CCPA East and CCPA North-West using several methods (Table 4). The molecular coancestry method resulted in lower $N_{e}$ estimates [North-West: $N_{e}=8.9$ (95\% CI 3.7-16.2); East: $N_{e}=14.0$ (95\% CI 7.2-23.0)] than the linkage disequilibrium method [North-West: $N_{e}=34.9$ (95\% CI 25.4-48.1); East: $N_{e}=36.1$ (95\% CI 29.1-44.6)]. Imprecise $N_{e}$ estimates (i.e. large confidence intervals) were produced for CCPA East using several temporal methods.

A recent bottleneck was detected in Finnish wolverines, as the Wilcoxon's sign-rank test showed a significant excess of heterozygotes $(\mathrm{P}<0.001)$. Furthermore, when tested separately on both CCPAs, CCPA East had a significant excess of heterozygotes $(\mathrm{P}<0.001)$ but not CCPA NorthWest $(\mathrm{P}=0.059)$. Additionally, Garza-Williamson modified indices suggested a bottleneck for both CCPAs $\left[M_{\text {North-West }}\right.$ $\left.=0.49( \pm 0.12), M_{\text {East }}=0.52( \pm 0.12)\right]$.

\section{mtDNA}

The analysis of mtDNA sequences demonstrated the presence of two haplotypes in Finland (Fig. 4). A common haplotype was found in $80.5 \%$ of individuals in Finland (in CCPA North, 90.3\% and in CCPA East 80.0\%) (Fig. S14). A rarer haplotype (19.5\%), differentiating by five substitutions on 579 bp, was more prevalent in CCPA East (20.0\%) than in CCPA North (9.7\%). In CCPA North, the occurrence of the rare haplotype was restricted to the southernmost parts. All sequenced individuals from CCPA West $(N=03)$ carried the rare haplotype. The common haplotype was identical to haplotype 15 (Zigouris et al. 2013), which was found in wolverine populations in Sweden (Arnason et al. 2007; Ekblom et al. 2014), Far East Russia (Tomasik and Cook 2005) and North America (Zigouris et al. 2013). The rare haplotype

Table 2 Estimated genetic diversity for both CCPAs given by number of alleles $(A)$, allelic richness $\left(A_{R}\right)$, private allelic richness $\left(A_{P}\right)$, expected heterozygosity $\left(H_{E}\right)$, observed heterozygosity $\left(H_{O}\right)$ and inbreeding coefficients $\left(F_{I S}\right)$

\begin{tabular}{|c|c|c|c|c|c|c|c|c|c|c|c|c|}
\hline & \multicolumn{6}{|c|}{ North-West $(\mathrm{n}=114)$} & \multicolumn{6}{|c|}{ East $(\mathrm{n}=138)$} \\
\hline & $A$ & $A_{R}$ & $A_{P}$ & $H_{E}$ & $H_{O}$ & $F_{I S}$ & $A$ & $A_{R}$ & $A_{P}$ & $H_{E}$ & $H_{O}$ & $F_{I S}$ \\
\hline Mean & 3.8 & 3.7 & 0.06 & 0.489 & 0.470 & 0.01 & 4.07 & 4.0 & 0.28 & 0.568 & 0.560 & -0.02 \\
\hline SD & 1.4 & 1.4 & 0.12 & 0.178 & 0.158 & & 1.54 & 1.5 & 0.40 & 0.104 & 0.113 & \\
\hline
\end{tabular}

$A_{R}$ and $A_{P}$ were set according to the lowest number of 184 genes 
Table 3 Mean estimated genetic diversity given by number of alleles $(A)$, allelic richness $\left(A_{R}\right)$, private allelic richness $\left(A_{P}\right)$, expected heterozygosity $\left(H_{E}\right)$, observed heterozygosity $\left(H_{O}\right)$, inbreeding coefficients $\left(F_{I S}\right)$, the number of linked markers (LD) and the assignment probability $(q)$ for both CCPAs divided by buffers with increasing distance from the contact zone. Each buffer has a width of 150 km (Fig. S2). $A_{R}$ and $A_{P}$ were set according to the lowest number of genes. Significant $F_{I S}$-values are marked with asterisk

\begin{tabular}{|c|c|c|c|c|c|c|c|c|c|c|c|c|c|c|c|c|c|c|}
\hline & \multicolumn{9}{|c|}{ North } & \multicolumn{9}{|c|}{ East } \\
\hline & $N$ & $A$ & $A_{R}$ & $A_{P}$ & $H_{E}$ & $H_{O}$ & $F_{I S}$ & LD & $q$ & $N$ & $A$ & $A_{R}$ & $A_{P}$ & $H_{E}$ & $H_{O}$ & $F_{I S}$ & LD & $q$ \\
\hline \multicolumn{19}{|l|}{ Buffer 1} \\
\hline Mean & 22 & 3.5 & 3.1 & 0.03 & 0.527 & 0.548 & -0.0394 & $0 / 91$ & 0.80 & 11 & 3.4 & 3.2 & 0.04 & 0.552 & 0.533 & 0.0383 & $0 / 91$ & 0.78 \\
\hline SD & & 1.1 & & & 0.178 & 0.188 & & & 0.25 & & 1.2 & & & 0.177 & 0.225 & & & 0.24 \\
\hline \multicolumn{19}{|l|}{ Buffer 2} \\
\hline Mean & 69 & 3.4 & 2.8 & 0.06 & 0.463 & 0.451 & 0.0277 & $3 / 91$ & 0.92 & 12 & 3.2 & 3.1 & 0.05 & 0.544 & 0.477 & $0.1236^{*}$ & $0 / 91$ & 0.86 \\
\hline SD & & 1.3 & & & 0.189 & 0.177 & & & 0.18 & & 1.1 & & & 0.164 & 0.219 & & & 0.15 \\
\hline \multicolumn{19}{|l|}{ Buffer 3} \\
\hline Mean & 16 & 2.8 & 2.6 & 0.02 & 0.521 & 0.497 & 0.0478 & $0 / 91$ & 0.94 & 62 & 3.6 & 3.0 & 0.05 & 0.548 & 0.570 & -0.0417 & $3 / 91$ & 0.87 \\
\hline SD & & 0.9 & & & 0.143 & 0.174 & & & 0.08 & & 1.4 & & & 0.127 & 0.145 & & & 0.24 \\
\hline \multicolumn{19}{|l|}{ Buffer 4} \\
\hline Mean & & & & & & & & & & 48 & 3.1 & 2.7 & 0.04 & 0.556 & 0.573 & -0.0350 & $2 / 91$ & 0.90 \\
\hline SD & & & & & & & & & & & 0.9 & & & 0.071 & 0.128 & & & 0.19 \\
\hline
\end{tabular}

$* \mathrm{P} \leq 0.05$

Table 4 Effective population size estimates for CCPA clusters using different methods in NeESTIMATOR (95\% confidence intervals jackknifed on loci within brackets)

\begin{tabular}{|c|c|c|c|c|c|c|}
\hline & \multirow{2}{*}{$\begin{array}{l}\text { Linkage disequilib- } \\
\text { rium }\end{array}$} & \multirow[t]{2}{*}{ Molecular coancestry } & \multicolumn{3}{|l|}{ Temporal } & \\
\hline & & & Pollak & Nei/Tajima & Jorde/Ryman & \\
\hline \multirow[t]{2}{*}{ North-West $(N=114)$} & $34.9(25.4-48.1)$ & $8.9(3.7-16.2)$ & & & & \\
\hline & & & $22.4(12.9-46.6)$ & $20.5(11.8-41.8)$ & $14.2(9.2-29.9)$ & $\begin{array}{c}2007-2012 \text { vs. } \\
2013-2018\end{array}$ \\
\hline \multirow[t]{4}{*}{ East $(N=138)$} & $36.1(29.1-44.6)$ & $14.0(7.2-23.0)$ & & & & \\
\hline & & & $59.5(11.2-\infty)$ & NA $(15.1-\infty)$ & NA $(19.9-\infty)$ & $\begin{array}{c}2001-2006 \text { vs. } \\
2007-2012\end{array}$ \\
\hline & & & $46.8(19.1-489.3)$ & $60.2(20.9-\infty)$ & $79.2(21.8-\infty)$ & $\begin{array}{c}2001-2006 \text { vs. } \\
2013-2018\end{array}$ \\
\hline & & & $30.8(11.3-\infty)$ & $35.4(12.9-\infty)$ & $36.4(14.1-\infty)$ & $\begin{array}{c}2007-2012 \text { vs. } \\
2013-2018\end{array}$ \\
\hline
\end{tabular}

Considering the temporal analysis, the CCPA North-West had two temporal clusters: 2007-2012 $(N=47)$ and $2013-2018(N=63)$; while the CCPA East had three temporal clusters: 2001-2006 $(N=19), 2007-2012(N=23)$ and 2013-2018 $(N=26)$. For two estimates we got unrealistically large or negative values likely due to the method not being accurate for our data, which were marked as "NA" in the table. For more details, see "Material and methods"

has not been found in previous studies. The mean nucleotide diversity $(\pi)$ of wolverines in Finland was 0.00272 and the haplotype diversity $(\hat{h})$ was 0.315 . The nucleotide and haplotype diversities were higher in CCPA East $(\pi=0.00279$, $\hat{h}=0.323)$ than in CCPA North $(\pi=0.00156, \hat{h}=0.181)$. 


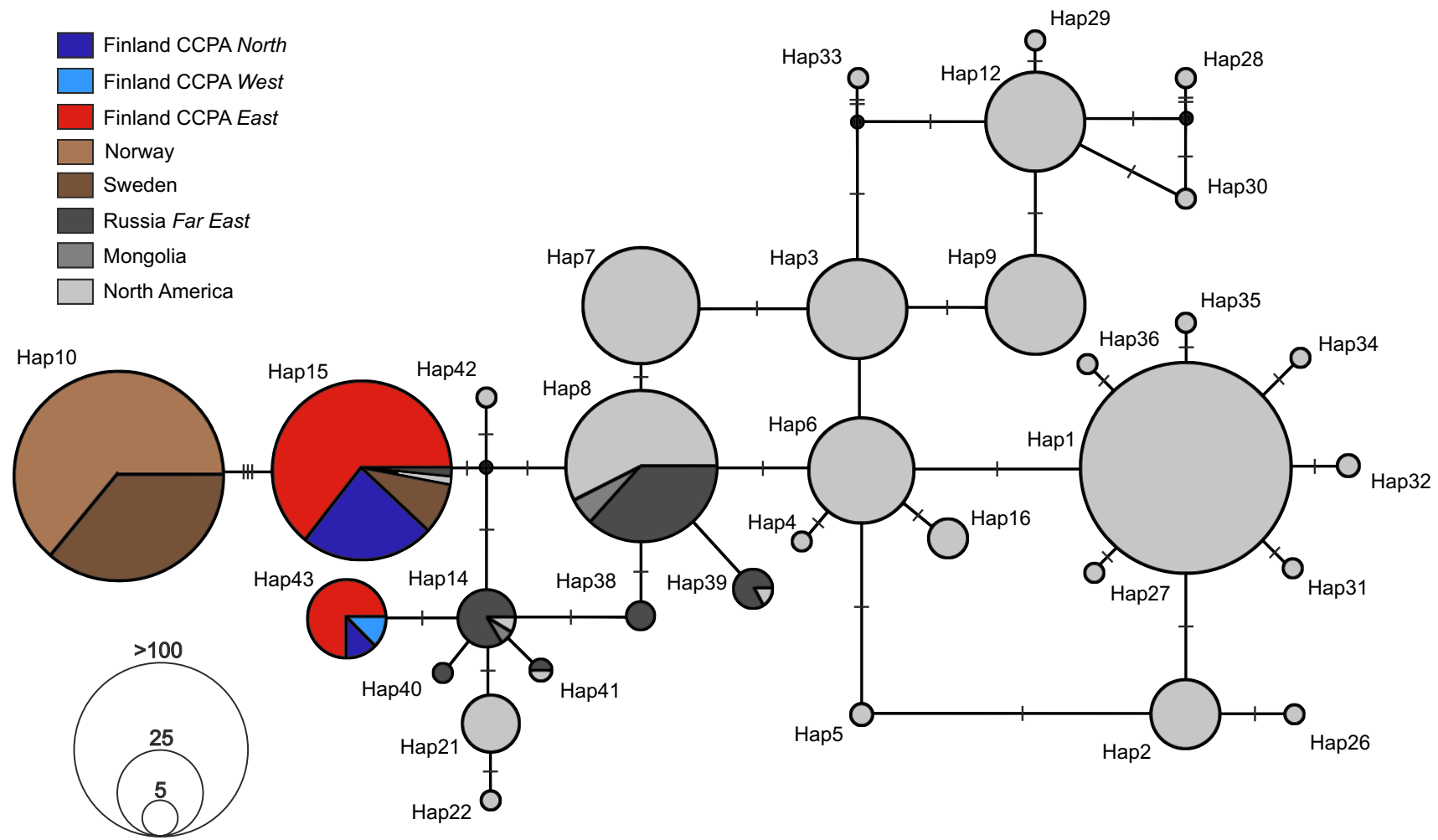

Fig. 4 Median-joining haplotype network reconstructed from a short fragment $(317 \mathrm{bp})$ of the mtDNA control region for wolverines $(N$ $=1033$ ) using Network. Node sizes are proportional to haplotype frequencies. The proportion of sampling localities is shown within each node. Each black perpendicular line represents a point mutation. Median vectors are represented with black nodes. The haplotype numbers are named after Zigouris et al. (2013), except for haplotype 43 (new from this study). All Finnish sequences $(N=129)$ are from this study. Some earlier recognized haplotypes merged with other

\section{Discussion}

\section{Genetic structure}

In this study, we assessed putatively neutral genetic variation (microsatellites and mtDNA) in a population of wolverines that is recovering from a recent population bottleneck. Based on microsatellites, we identified two major genetic clusters of wolverines in Finland, a northern (CCPA North-West) and eastern cluster (CCPA East). Both Bayesian and nonBayesian clustering methods supported the same two genetic clusters, however, varying in the strength of subdivision. The spatial scale of the clusters is consistent with the genetic structure of other wolverine populations that experienced range contractions in Scandinavia (Walker et al. 2001; Flagstad et al. 2004; Ekblom et al. 2018), at the peripheral part of the wolverine distribution in eastern Canada (Zigouris et al. 2012) and in the north-western US (Kyle and Strobeck 2001, 2002; Cegelski et al. 2006). Interestingly, similar clusters with contact zones in northern Finland have been found in haplotypes due to using a short fragment [as in Zigouris et al. 2013: Hap11 merges with Hap1, Hap13 with Hap6, Hap23 (North America) with Hap14 (Russia and Mongolia)]. Note that haplotype 10 is likely the same as haplotype 15 (see "Discussion"). The other sequences were obtained via GenBank from: Wilson et al. (2000), Tomasik and Cook (2005), Arnason et al. (2007), Schwartz et al. (2007), Frances (2008), Ekblom et al. (2014), Zigouris et al. (2013) and Malyarchuk et al. (2015)

other species co-occurring in the area with, at present, a continuous distribution (Carlsson et al. 2004; Kopatz et al. 2014; Honnen et al. 2015; Kangas et al. 2015),

We found a significant pattern of IBD across the whole study area. A strong pattern of IBD can cause an overestimation of clusters, leading to incorrect interpretation of population structure (Frantz et al. 2009). If the appearance of major population clusters could be explained by IBD, we would expect that the population structure would be consistent with a clinal change, however, without affecting the spatial genetic diversity. Contrastingly, when two divergent clusters meet each other, the population at the contact zone is expected to be more admixed and have a higher genetic diversity and inbreeding coefficient (Wahlund's effect 1928), as well as increased linkage disequilibrium (Slatkin 2008), compared to sites further from the contact zone. We observed stronger admixture and higher allelic richness towards the contact zone, but no increase in expected heterozygosity, the inbreeding coefficient and the number of linked markers. Especially in the CCPA East, the 
mixed genetic ancestry due to former translocations might have diluted the expected signs of admixture. Based on these results, we suggest that IBD plays an important role in shaping the contemporary genetic population structure of wolverines, consistent with previous studies in other wolverine populations (e.g. Kyle and Strobeck 2002; Rico et al. 2015; Ekblom et al. 2018). To rule out that the two clusters are an artefact of discontinuous sampling in a population with IBD (Tucker et al. 2014), sampling has to be extended to Russian Karelia.

We found that CCPA East and CCPA North-West are connected but significantly differentiated $\left(F_{S T}=0.100\right)$. The genetic differentiation within Finland is stronger than what was found previously for wolverines between northern Scandinavia and southern Norway $\left(F_{S T}=0.045-0.088\right)$, also based on microsatellites (Walker et al. 2001; Flagstad et al. 2004). When compared to North American wolverine populations (Kyle and Strobeck 2002; Cegelski et al. 2006; Zigouris et al. 2012), an $F_{S T}$ estimate of the same magnitude as between the Finnish clusters seems to be typical among peripheral populations. A microsatellite study on coexisting brown bears (Kopatz et al. 2014) found a similar division of genetic clusters between north and southeast Finland. Nevertheless, low population differentiation was detected $\left(F_{S T}=0.025\right)$ due to strong recovery after a bottleneck, fading out temporary population subdivision (Kopatz et al. 2014; Hagen et al. 2015). Indeed, wolverine numbers in Finland have increased during the last decades, however, not as much as the number of bears (Hagen et al. 2015). The slower recovery of wolverines compared to bears can be ascribed to the intensity of the bottleneck. Whereas the minimum of bears was estimated to be 150 individuals in 1970 (Pulliainen 1990), wolverines were at the same time nearly extirpated from Finland (Pulliainen 1982). Therefore, clusters detected in this study might very well represent the subdivision of the wolverine population during the bottleneck. There are no evident geographical barriers limiting movements of individuals between the clusters. The reindeer husbandry area of Finland (Fig. 1) does not seem to constitute a barrier between the clusters either, as the supposed contact zone is situated $300 \mathrm{~km}$ north from the southernmost reindeer husbandry areas. Finally, genetic clusters based on microsatellites do not necessary reflect that wolverines are locally adapted (Rico et al. 2015).

We found genetic evidence of the translocation history in Finnish wolverines. The high genetic similarity between northern Finnish Lapland (CCPA North) and western Finland (CCPA West) is likely due to the translocations that took place in the end of the twentieth century (Fig. 2). At that time, there were no wolverines in western Finland. This type of high similarity between the source and the translocated populations have previously been described also in other cases of reintroductions to areas where the species had completely disappeared (Wisely et al. 2003; Mowry et al. 2015). Our results suggest that the translocated wolverines have survived and reproduced for decades in western Finland. Indeed, translocations have the ability to alter the genetic make-up of populations and the genetic signature of translocations can remain detectable for a long time (Puckett et al. 2014; Grauer et al. 2017; Hapeman et al. 2017). However, we did not detect signs of expansion from the western cluster towards the east but rather an expansion of the natural eastern cluster to the west. Although, we did not observe any temporal change of clusters through time, we assume that admixture will increase considering the dispersal capacity of wolverines (Gardner et al. 1986; Vangen et al. 2001; Flagstad et al. 2004; Inman et al. 2012) and the recent population growth (Frosch et al. 2014; Hagen et al. 2015; Pigneur et al. 2019).

In our study, population structure based on microsatellites and mtDNA did not match perfectly. We found two mtDNA haplotypes within Finland. The common haplotype is the same as the only haplotype found in Scandinavia (haplotype 15) by Arnason et al. (2007) and Ekblom et al. (2014), and likely the same as the haplotype described by Walker et al. (2001) (Fig. 4; Zigouris et al. 2013) for Scandinavia (haplotype 10). This haplotype 10 was found in 169 individuals by SSCP, but sequenced only from 2 (Walker et al. 2001). These sequences differ from haplotype 15 by 3 substitutions, but most likely represent the same haplotype because none of the previous studies has detected more than 1 haplotype from Scandinavia. The rarer Finnish haplotype (hereafter haplotype 43) has not been detected previously in wolverines and is the closest to a haplotype found previously in Far East Russia and Mongolia (haplotype 14). Haplotype 43 was more abundant in CCPA East $(20.0 \%)$ than in CCPA North $(9.7 \%)$. The low occurrence $(N=03)$ of haplotype 43 in CCPA North could be explained by for example a single female dispersal event from the east. Similarly, the occurrence of haplotype 43 in all samples of CCPA West $(N=03)$, could be explained by the coincidence that some of the translocated females ( 2 out of 6 with an eastern origin) happened to carry this haplotype. Alternatively, it could be due to secondary contact after the recovery of CCPA East or a combination of these scenarios. This remains speculative, however, due to the low number of samples from western Finland.

In contrast to the microsatellite analyses, mtDNA haplotypes were not clearly spatially distributed within Finland. Haplotype 43 was, nevertheless, mostly present throughout eastern and western Finland but with no clear clustering pattern. In studies on the genetic structure of wolverines in North America, differences between these markers were linked to female philopatry, male-biased dispersal, long term population fragmentation and current variation in gene flow between regions (Chappell et al. 2004; Tomasik and Cook 2005; Cegelski et al. 2006; Schwartz et al. 2007; Zigouris 
et al. 2012). Nuclear markers showed no population structure in large continuous wolverine populations, whereas mtDNA did (Wilson et al. 2000; Kyle and Strobeck 2001, 2002; Chappell et al. 2004). Importantly though, nuclear markerbased population structure is becoming more apparent towards the periphery of wolverine's distribution (Kyle and Strobeck 2001, 2002; Cegelski et al. 2003, 2006; Zigouris et al. 2012). Our results on microsatellites fit well with the common assumption that peripheral wolverine populations exhibit significant population structure and points towards limited gene flow throughout Finland.

The fact that only two distinct mtDNA haplotypes are found in Fennoscandia so far could imply that Fennoscandian wolverine populations have lost haplotypes due to a recent bottleneck or a post-glacial founder effect. Walker et al. (2001) suggested that the cause of a single mtDNA haplotype in Scandinavia lies in a post-glacial founder effect, as the authors did not find any other haplotypes in their 10 pre-bottleneck (1922-1968) samples. The existence of haplotype 43 in Finland, especially in CCPA East, could have arisen when the species colonized Finland via a north-eastern route (Jaarola et al. 1999). On the other hand, European archaeological material from the Late Glacial Period shows that wolverines were roaming far south of their current range (Sommer and Benecke 2004), suggesting that after the LGM a bidirectional re-colonization of Fennoscandia is possible. Colonization via both routes were described for brown bears using ancient mtDNA sequences (Bray et al. 2013) as well as for other boreal mammals in Fennoscandia (Ruiz-González et al. 2013; Kangas et al. 2015; Wallén et al. 2018). The widespread haplotype 15 in Fennoscandia, although found in Far East Russia and Mongolia, could have a European origin, whereas haplotype 43 could have an eastern origin. Alternatively, the severe recent bottleneck might have impacted the genetic make-up of the Fennoscandian wolverine population by removing other haplotypes (Nei et al. 1975). Haplotype 43 might then relate to a relict population, which was more common in Finland before the bottleneck. It was present already in our oldest (1983-1991) samples of CCPA East $(N=02)$, but a wider temporal and geographical sampling scheme is needed to resolve the origin of the two haplotypes.

Altogether, we suggest that the genetic population structure of wolverines in Finland is due to the combined effects of a genetic cline from east to north caused by IBD, past demographic events and translocation history. The two applied markers provided different insights into how population history has shaped the genetic structure. Further transboundary studies are needed to study possible additional effects of isolation-by-resistance (IBR; McRae 2006) and putative barriers to gene flow. The amount of dispersing wolverines between the clusters appears low considering the innate travel capacity (Gardner et al. 1986; Vangen et al. 2001; Flagstad et al. 2004; Inman et al. 2012). During the last two decades, only a few migrants were detected between the clusters. As we did not sample the Russian part of Karelia, we might have missed migration events due to wolverines using forest corridors in Russian Karelia (Lindén et al. 2000).

\section{Genetic diversity}

Genetic diversity was in general higher in CCPA East $\left(H_{E}=\right.$ 0.57, $\left.A_{R}=4.0, A_{P}=0.3\right)$ than in CCPA North-West $\left(H_{E}=\right.$ $\left.0.49, A_{R}=3.7, A_{P}=0.1\right)$. As each study uses a partially different set of microsatellites, comparison of diversity measures should be interpreted with caution. Nevertheless, the heterozygosity estimate of CCPA North-West $\left(H_{E}=0.49\right)$ is lower than in previous studies reported for Scandinavian wolverines from their southern $\left(H_{E}=0.53\right)$, northern $\left(H_{E}\right.$ $=0.51)\left(\right.$ Flagstad et al. 2004) and central range $\left(H_{E}=0.51\right)$ (Hedmark and Ellegren 2007). The lowest heterozygosity estimates within Fennoscandia has been obtained from two newly founded subpopulations that were established in central Sweden $\left(H_{E}=0.41\right.$ and $\left.H_{E}=0.39\right)$ (Hedmark and Ellegren 2007). Generally, the allelic richness in Finland $\left(A_{R \text { East }}=4.0, A_{R \text { North-West }}=3.7\right)$ was higher than in central Scandinavia $\left(A_{R}=3.0\right)$ (Hedmark and Ellegren 2007). Especially CCPA East has been expanding during the last decade, which might explain the higher estimates of genetic diversity. Likewise, a minor increase in genetic variability has been observed in peripheral, expanding North American wolverine populations (Zigouris et al. 2012). In addition, proximity to larger Russian populations might elevate genetic diversity by bringing in new alleles. Lower variation in CCPA North-West suggests that this population, as part of the peripheral Scandinavian population (Boitani et al. 2015), might receive only limited gene flow, comparable to peripheral wolverine populations of the north-western US (Cegelski et al. 2006).

\section{Effective population size}

The two wolverine clusters in Finland have considerably low effective population sizes based on our microsatellite data, with several methods resulting in current $N_{e}<50$. Alarmingly, low estimates were detected for both Finnish clusters, even though they are assumingly part of larger transboundary wolverine populations. CCPA North-West belongs likely to the Scandinavian population (Boitani et al. 2015), where a current $N_{e}$ of 87 individuals was estimated using neutral SNP markers (Ekblom et al. 2018). The difference between the estimates might be caused by sampling bias and number of loci used (Antao et al. 2011; Luikart et al. 2010). In our study using 14 multi-allelic microsatellites, the assumption of random sampling was violated by including only northern 
Finnish samples for estimation of $N_{e}$ for the Scandinavian population, whereas a wider sampling scheme throughout Sweden and Norway was applied in Ekblom et al. (2018) using 384 bi-allelic SNPs.

Effective population sizes are expected to decrease from core populations to edge populations (Vucetich and Waite 2003). Therefore, we would have expected that $N_{e}$ of CCPA East could have been higher than in CCPA North-West. As $N_{e}$ estimates were low, it is possible that CCPA East is not a part of a larger Eurasian core population. The main corridor to connect taiga species of Fennoscandia with larger taiga complexes in Russia is located between the White Sea and Lake Onega (Lindén et al. 2000). As wolverines are currently not found south of Lake Onega (Danilov et al. 2018), restricted connectivity through this isthmus might limit gene flow and separate the Karelian population from the Arkhangelsk population. Furthermore, low $N_{e}$ suggest that both Finnish clusters are still recovering from the recent bottleneck and/or gene flow is limited. Comparable $N_{e}$ estimates have been found in other large mammals, if a population has gone through a bottleneck and/or are isolated (e.g. Saimaa ringed seal Phoca hispida saimensis: $N_{e}=11-113$, Valtonen et al. 2014; Finnish wolves (Canis lupus): $N_{e}=38-43$ Aspi et al. 2006; Iberian lynxes Lynx pardinus: $N_{e}=8-23$ CasasMarce et al. 2013; insular Canada lynx Lynx canadensis: $N_{e}=7-8$ Prentice et al. 2017). However, similar estimates have been obtained also for stable populations with ongoing migration (e.g. brown bears: $N_{e}=9-37$ Schregel et al. 2012; cougar Puma concolor: $N_{e}=38-112$ Juarez et al. 2016).

\section{Implications to conservation management}

For the conservation of wolverines in northern Europe, connectivity throughout the range is of utmost importance to retain genetic variation. Our study shows that wolverines in Finland are divided in two genetic clusters, which reflect well the subdivided population at the time of the bottleneck. Furthermore, the eastern cluster contains an mtDNA haplotype not present in the rest of Scandinavia and especially the northern cluster had low genetic diversity. To sustain gene flow from Karelia towards Scandinavia, connectivity between the Finnish eastern and northern clusters is crucial and additionally, persistence of the western cluster should be monitored. The Finnish wolverine population has endured times of persecution but is making a comeback to its former range. Importantly, the recent recolonization of wolverines into the boreal forest of Sweden shows that the species is flexible, when circumstances are beneficial (Aronsson and Persson 2017). The positive attitude towards wolverines outside the reindeer husbandry area also facilitates the establishment of wolverines into less optimal habitat (PohjaMykrä and Kurki 2008). In addition, local accumulations of snow are often sufficient to provide den sites (Pulliainen
1968; Magoun et al. 2017), even in regions where the average snow depth is low.

Due to climate change, wolverine habitat is expected to decrease and become more fragmented (McKelvey et al. 2011). Although, wolverine numbers in Finland are increasing, the bottleneck has altered the genetic make-up. Furthermore, temporary population growth does not necessarily secure a long-term, genetically diverse population (Jansson et al. 2012). Therefore, the level of connectivity with other extant population clusters in Eurasia needs to be resolved in order to propose management decisions, which are relevant for the conservation of wolverines throughout the range.

Acknowledgements Open access funding provided by University of Oulu including Oulu University Hospital. We thank the anonymous reviewers for their constructive feedback. We are grateful to all field workers for their tremendous sampling effort. In particular, we would like to thank Reima Ovaskainen, Esa Leinonen, Tapio Visuri, Seppo Ronkainen, Leo Korhonen (all working for the Natural Resources Institute Finland), Alpo Komulainen and the team of Metsähallitus for hair and scat sampling. We thank employees from Ruokavirasto and Natural Resources Institute Finland for providing the tissue samples and the lab technicians of the Norwegian Institute for Nature Research for analysing part of the samples. In addition, we would like to thank Marja Hyvärinen for her help with analysing the samples at the University of Oulu. This work was supported by the Finnish Ministry of Agriculture and Forestry, Academy of Finland (131673), Jenny and Antti Wihuri Foundation, Central Fund of the Finnish Cultural Foundation, Finnish Game Foundation, Finnish Foundation for Nature Conservation, Emil Aaltonen Foundation, Kuopion Luonnon Ystäväin yhdistys ry and Oulun Luonnonystävien yhdistys ry.

Open Access This article is licensed under a Creative Commons Attribution 4.0 International License, which permits use, sharing, adaptation, distribution and reproduction in any medium or format, as long as you give appropriate credit to the original author(s) and the source, provide a link to the Creative Commons licence, and indicate if changes were made. The images or other third party material in this article are included in the article's Creative Commons licence, unless indicated otherwise in a credit line to the material. If material is not included in the article's Creative Commons licence and your intended use is not permitted by statutory regulation or exceeds the permitted use, you will need to obtain permission directly from the copyright holder. To view a copy of this licence, visit http://creativecommons.org/licenses/by/4.0/.

\section{References}

Abramov AV (2016) Gulo gulo. The IUCN Red List of Threatened Species 2016. e.T9561A45198537

Antao T, Pérez-Figueroa A, Luikart G (2011) Early detection of population declines: high power of genetic monitoring using effective population size estimators. Evol Appl 4:144-154. https://doi.org /10.1111/j.1752-4571.2010.00150.x

Arnason U, Gullberg A, Janke A, Kullberg M (2007) Mitogenomic analyses of caniform relationships. Mol Phylogenet Evol 45:863874. https://doi.org/10.1016/j.ympev.2007.06.019

Aronsson M, Persson J (2017) Mismatch between goals and the scale of actions constrains adaptive carnivore management: the case of the wolverine in Sweden. Anim Conserv 20:261-269. https:// doi.org/10.1111/acv.12310 
Aspi J, Roininen E, Ruokonen M, Kojola I, Vilà C (2006) Genetic diversity, population structure, effective population size and demographic history of the Finnish wolf population. Mol Ecol 15:1561-1576. https://doi.org/10.1111/j.1365-294X.2006.02877 . $\mathrm{x}$

Bandelt H-J, Forster P, Röhl A (1999) Median-joining networks for inferring intraspecific phylogenies. Mol Biol Evol 16:37-48. https://doi.org/10.1093/oxfordjournals.molbev.a026036

Berry O, Tocher MD, Sarre SD (2004) Can assignment tests measure dispersal? Mol Ecol 13:551-561. https://doi. org/10.1046/j.1365-294X.2004.2081.x

Bischof R, Gregersen ER, Brøseth H, Ellegren H, Flagstad Ø (2016) Noninvasive genetic sampling reveals intrasex territoriality in wolverines. Ecol Evol 6:1527-1536. https://doi.org/10.1002/ ece 3.1983

Boitani L, Alvarez F, Anders O, Andren H, Avanzinelli E, Balys V, Blanco JC, Breitenmoser U, Chapron G, Ciucci P (2015) Key actions for large carnivore populations in Europe. Institute of Applied Ecology (Rome, Italy). Report to DG Environment, European Commission, Bruxelles. Contract no. 07.0307/2013/654446/SER/B3

Bray SCE, Austin JJ, Metcalf JL, Østbye K, Østbye E, Lauritzen S, Aaris-Sørensen K, Valdiosera C, Adler CJ, Cooper A (2013) Ancient DNA identifies post-glacial recolonisation, not recent bottlenecks, as the primary driver of contemporary mtDNA phylogeography and diversity in Scandinavian brown bears. Diversity Distrib 19:245-256. https://doi.org/10.111 1/j.1472-4642.2012.00923.x

Broquet T, Petit E (2004) Quantifying genotyping errors in noninvasive population genetics. Mol Ecol 13:3601-3608. https://doi. org/10.1111/j.1365294X.2004.02352.x

Brøseth H, Flagstad Ø, Wärdig C, Johansson M, Ellegren H (2010) Large-scale noninvasive genetic monitoring of wolverines using scats reveals density dependent adult survival. Biol Conserv 143:113-120. https://doi.org/10.1016/j.biocon.2009.09.012

Carlsson M, Söderberg L, Tegelström H (2004) The genetic structure of adders (Vipera berus) in Fennoscandia: congruence between different kinds of genetic markers. Mol Ecol 13:3147-3152. https ://doi.org/10.1111/j.1365-294X.2004.02315.x

Casas-Marce M, Soriano L, López-Bao JV, Godoy JA (2013) Genetics at the verge of extinction: insights from the Iberian lynx. Mol Ecol 22:5503-5515. https://doi.org/10.1111/mec.12498

Cegelski CC, Waits LP, Anderson J (2003) Assessing population structure and gene flow in Montana wolverines (Gulo gulo) using assignment-based approaches. Mol Ecol 12:297-2918. https:// doi.org/10.1046/j.1365-294X.2003.01969.x

Cegelski CC, Waits LP, Anderson NJ, Flagstad Ø, Strobeck C, Kyle CJ (2006) Genetic diversity and population structure of wolverine (Gulo gulo) populations at the southern edge of their current distribution in North America with implications for genetic viability. Conserv Genet 7:1566-1572. https://doi.org/10.1007/ s10592-006-9126-9

Chappell DE, Van Den Bussche RA, Krizan J, Patterson B (2004) Contrasting levels of genetic differentiation among populations of wolverines (Gulo gulo) for northern Canada revealed by nuclear and mitochondrial loci. Conserv Genet 5:759-767. https://doi. org/10.1007/s10592-004-1976-4

Chapron G, Kaczensky P, Linnell JDC et al (2014) Recovery of large carnivores in Europe's modern human-dominated landscapes. Science 346:1517-1519. https://doi.org/10.1126/science.12575 53

Crooks KR (2002) Relative sensitivities of mammalian carnivores to habitat fragmentation. Conserv Biol 16:488-502. https://doi.org /10.1046/j.1523-1739.2002.00386.x

Crooks KR, Burdett CL, Theobald DM, Rondinini C, Boitani L (2011) Global patterns of fragmentation and connectivity of mammalian carnivore habitat. Philos Trans R Soc Lond B Biol Sci 366:26422651. https://doi.org/10.1098/rstb.2011.0120

Danilov PI, Panchenko DV, Tirronen KF, Fyodorov FV, Belkin VV (2018) Changes in Mammal Fauna of the Northern Palearctic and Living Range Dynamics of the Component Species. Biol Bull 45:265-277. https://doi.org/10.1134/S1062359018030032

Davis CS, Strobeck C (1998) Isolation, variability, and cross-species amplification of polymorphic microsatellite loci in the family Mustelidae. Mol Ecol 7:1776-1778

Di Rienzo A, Peterson AC, Garza JC, Valdes AM, Slatkin M, Freimer NB (1994) Mutational processes of simple-sequence repeat loci in human populations. Proc Natl Acad Sci U S A 91:3166-3170. https://doi.org/10.1073/pnas.91.8.3166

Diniz-Filho JAF, Soares TN, Lima JS, Dobrovolski R, Landeiro VL, de Campos Telles MP, Rangel TF, Bini LM (2013) Mantel test in population genetics. Genet Mol Biol 36:475-485. https:// doi.org/10.1590/S1415-47572013000400002

Do C, Waples RS, Peel D, Macbeth GM, Tillett BJ, Ovenden JR (2014) NeEstimator v2: re-implementation of software for the estimation of contemporary effective population size $(\mathrm{Ne})$ from genetic data. Mol Ecol Resour 14:209-214. https://doi. org/10.1111/1755-0998.12157

Duffy AJ, Landa A, O'Connell M, Stratton C, Wright JM (1998) Four polymorphic microsatellites in wolverine, Gulo gulo. Anim Genet 29:63-72. https://doi.org/10.104 6/j.1365-2052.1998.00221.x

Ekblom R, Smeds L, Ellegren H (2014) Patterns of sequencing coverage bias revealed by ultra-deep sequencing of vertebrate mitochondria. BMC Genom 15:467. https://doi. org/10.1186/1471-2164-15-467

Ekblom R, Brechlin B, Persson J, Smeds L, Johansson M, Magnusson J, Flagstad Ø, Ellegren H (2018) Genome sequencing and conservation genomics in the Scandinavian wolverine population. Conserv Biol 32:1301-1312. https://doi.org/10.1111/ cobi. 13157

Ermala A (2003) A Survey of Large Predators in Finland during the 19th-20th Centuries. Acta Zool Litu 13:15-20. https://doi. org/10.1080/13921657.2003.10512538

Evanno G, Regnaut S, Goudet J (2005) Detecting the number of clusters of individuals using the software structure: a simulation study. Mol Ecol 14:2611-2620. https://doi.org/10.1111/j.1365294X.2005.02553.x

Excoffier L, Lischer HEL (2010) Arlequin suite ver 3.5: a new series of programs to perform population genetics analyses under Linux and Windows. Mol Ecol Resour 10:564-567. https://doi.org/10. 1111/j.1755-0998.2010.02847.x

Falush D, Stephens M, Pritchard JK (2003) Inference of population structure using multilocus genotype data: linked loci and correlated allele frequencies. Genetics 164:1567-1587

Fisher JT, Bradbury S, Anholt B, Nolan L, Roy L, Volpe JP, Wheatley M (2013) Wolverines (Gulo gulo luscus) on the Rocky Mountain slopes: natural heterogeneity and landscape alteration as predictors of distribution. Can J Zool 91:706-716. https://doi. org/10.1139/cjz-2013-0022

Flagstad Ø, Hedmark E, Landa A, Brøseth H, Persson J, Andersen R, Segerström P, Ellegren H (2004) Colonization History and Noninvasive Monitoring of a Reestablished Wolverine Population. Conserv Biol 18:676-688. https://doi.org/10.111 $1 / \mathrm{j} .1523-1739.2004 .00328 . \mathrm{x}-\mathrm{i} 1$

Flagstad $\varnothing$, Kleven O, Spets MH, Eriksen LB, Halvorsen BU, Andersskog IPØ, Hemphill EK, Johansson M, Ekblom R, Ellegren H, Brøseth H (2018) DNA-based monitoring of the Scandinavian wolverine population 2018. NINA Report 1592. Norwegian Institute for Nature Research

Fleming MA, Ostrander EA, Cook JA (1999) Microsatellite markers for American mink (Mustela vison) and ermine (Mustela 
erminea). Mol Ecol 8:1352-1355. https://doi.org/10.1046/ j.1365-294X.1999.00701_2.x

Frances J (2008) Spatial genetic structure and demographic history of wolverine in North America with an emphasis on peripheral populations. MSc Thesis. University of New Mexico, United States. 51p

Francis RM (2017) pophelper: an R package and web app to analyse and visualize population structure. Mol Ecol Resour 17:27-32. https://doi.org/10.1111/1755-0998.12509

Frankham R (2005) Genetics and extinction. Biol Conserv 126:131140. https://doi.org/10.1016/j.biocon.2005.05.002

Frankham R, Ballou JD, Briscoe DA (2010) Introduction to conservation genetics. Cambridge University Press

Frankham R, Bradshaw CJA, Brook BW (2014) Genetics in conservation management: Revised recommendations for the 50/500 rules, Red List criteria and population viability analyses. Biol Conserv 170:56-63. https://doi.org/10.1016/j.bioco n.2013.12.036

Frantz AC, Cellina S, Krier A, Schley L, Burke T (2009) Using spatial Bayesian methods to determine the genetic structure of a continuously distributed population: clusters or isolation by distance? J Appl Ecol 46:493-505. https://doi.org/10.111 1/j.1365-2664.2008.01606.x

Frosch C, Kraus RHS, Angst C, Allgöwer R, Michaux J, Teubner J, Nowak C (2014) The Genetic Legacy of Multiple Beaver Reintroductions in Central Europe. PLoS ONE 9(5):e97619. https:// doi.org/10.1371/journal.pone.0097619

Gardner CL, Ballard WB, Jessup RH (1986) Long Distance Movement by an Adult Wolverine. J Mammal 67:603-603. https://doi. org/10.2307/1381300

Garza JC, Williamson EG (2001) Detection of reduction in population size using data from microsatellite loci. Mol Ecol 10:305-318. https://doi.org/10.1046/j.1365-294X.2001.01190.x

Gervasi V, Brøseth H, Gimenez O, Nilsen EB, Odden J, Flagstad $\varnothing$, Linnell JDC (2016) Sharing data improves monitoring of trans-boundary populations: the case of wolverines in central Scandinavia. Wildlife Biol 22:95-106. https://doi.org/10.2981/ wlb.00142

Goudet J (2003) FSTAT (ver. 2.9.4.), a program to estimate and test population genetics parameters. Available from http://www.unil. ch/izea/softwares/fstat.html Updated from Goudet [1995]

Grauer JA, Gilbert JH, Woodford JE, Eklund D, Anderson S, Pauli JN (2017) Unexpected genetic composition of a reintroduced carnivore population. Biol Cons 215:246-253. https://doi. org/10.1016/j.biocon.2017.09.016

Hagen SB, Kopatz A, Aspi J, Kojola I, Eiken HG (2015) Evidence of rapid change in genetic structure and diversity during range expansion in a recovering large terrestrial carnivore. Proc R Soc B 282:20150092. https://doi.org/10.1098/rspb.2015.0092

Hapeman P, Latch EK, Rhodes OE, Swanson B, Kilpatrick CW (2017) Genetic population structure of fishers (Pekania pennanti) in the Great Lakes region: remnants and reintroductions. Can J Zool 95:869-876. https://doi.org/10.1139/cjz-2016-0325

Hardy OJ, Vekemans X (2002) spagedi: a versatile computer program to analyse spatial genetic structure at the individual or population levels. Mol Ecol Notes 2:618-620. https://doi.org/10.104 6/j.1471-8286.2002.00305.x

Hedmark E, Ellegren H (2007) DNA-based monitoring of two newly founded Scandinavian wolverine populations. Conserv Genet 8:843-852. https://doi.org/10.1007/s10592-006-9231-9

Hedmark E, Flagstad Ø, Segerström P, Persson J, Landa A, Ellegren H (2004) DNA-based individual and sex identification from wolverine (Gulo gulo) faeces and urine. Conserv Genet 5:405-410. https://doi.org/10.1023/B:COGE.0000031224.88778.f5

Hedmark E, Persson J, Segerström P, Landa A, Ellegren H (2007) Paternity and mating system in wolverines Gulo gulo.
Wildlife Biol 13:13-30. https://doi.org/10.2981/09096396(2007)13[13:PAMSIW]2.0.CO;2

Henriksen S, Hilmo O (eds) (2015) The 2015 Norwegian Red List for Species [Norsk rødliste for arter 2015]. Norwegian Biodiversity Information Centre, Trondheim

Hill WG (1981) Estimation of effective population size from data on linkage disequilibrium. Genet Res 38:209-216. https://doi. org/10.1017/S0016672300020553

Honnen AC, Roos A, Stjernberg T, Zachos FE (2015) Genetic analysis of Eurasian otters (Lutra lutra) reveals high admixture in Finland and pronounced differentiation in Sweden. Mamm Biol 80:47-53. https://doi.org/10.1016/j.mambio.2014.09.005

Hyvärinen E, Juslén A, Kemppainen E, Uddström A, Liukko U (2019) Suomen lajien uhanalaisuus - Punainen kirja 2019 (The 2019 Red List of Finnish Species). Ympäristöministeriö, Helsinki

Inman RM, Packila ML, Inman KH, Mccue AJ, White GC, Persson J, Aber BC, Orme ML, Alt KL, Cain SL, Fredrick JA, Oakleaf BJ, Sartorius SS (2012) Spatial ecology of wolverines at the southern periphery of distribution. J Wildl Manag 76:778-792. https://doi. org/10.1002/jwmg.289

Jaarola M, Tegelström H, Fredga K (1999) Colonization history in Fennoscandian rodents. Biol J Linn Soc 68:113-127. https://doi. org/10.1111/j.1095-8312.1999.tb01161.x

Jansson E, Ruokonen M, Kojola I, Aspi J (2012) Rise and fall of a wolf population: genetic diversity and structure during recovery, rapid expansion and drastic decline. Mol Ecol 21:5178-5193. https:// doi.org/10.1111/mec.12010

Jernsletten JLL, Klokov K (2002) Sustainable Reindeer Husbandry. Arctic Council 2000-2002. Centre for Saami Studies, University of Troms $\varnothing$, Troms $\varnothing$

Jombart T (2008) adegenet: a R package for the multivariate analysis of genetic markers. Bioinformatics 24:1403-1405. https://doi. org/10.1093/bioinformatics/btn129

Jombart T, Ahmed I (2011) adegenet 1.3-1: new tools for the analysis of genome-wide SNP data. Bioinformatics 27:3070-3071. https ://doi.org/10.1093/bioinformatics/btr521

Jones OR, Wang J (2010) COLONY: a program for parentage and sibship inference from multilocus genotype data. Mol Ecol Resour 10:551-555. https://doi.org/10.1111/j.1755-0998.2009.02787.x

Jorde PE, Ryman N (2007) Unbiased Estimator for Genetic Drift and Effective Population Size. Genetics 177:927-935. https://doi. org/10.1534/genetics.107.075481

Juarez RL, Schwartz MK, Pilgrim KL, Thompson DJ, Tucker SA, Smith JB, Jenks JA (2016) Assessing temporal genetic variation in a cougar population: influence of harvest and neighboring populations. Conserv Genet 17:379-388. https://doi.org/10.1007/ s10592-015-0790-5

Kalinowski ST (2005) hp-rare 1.0: a computer program for performing rarefaction on measures of allelic richness. Mol Ecol Notes 5:187-189. https://doi.org/10.1111/j.1471-8286.2004.00845.x

Kalinowski ST, Taper ML, Marshall TC (2007) Revising how the computer program CERVUS accommodates genotyping error increases success in paternity assignment. Mol Ecol 16:10991106. https://doi.org/10.1111/j.1365-294X.2007.03089.x

Kangas VM, Kvist L, Kholodova M, Nygrén T, Danilov P, Panchenko D, Fraimout A, Aspi J (2015) Evidence of post-glacial secondary contact and subsequent anthropogenic influence on the genetic composition of Fennoscandian moose (Alces alces). J Biogeogr 42:2197-2208. https://doi.org/10.1111/jbi.12582

Kojola I (2018) Ahmakanta kasvussa lähes koko maassa. https:// www.luke.fi/uutiset/ahmakanta-kasvussa-lahes-koko-maassa. Accessed Mar 8, 2019

Kopatz A, Eiken HG, Aspi J, Kojola I, Tobiassen C, Tirronen KF, Danilov PI, Hagen SB (2014) Admixture and gene flow from Russia in the recovering northern European Brown Bear (Ursus 
arctos). PLoS One 9(5):e97558. https://doi.org/10.1371/journ al.pone.0097558

Kopelman NM, Mayzel J, Jakobsson M, Rosenberg NA, Mayrose I (2015) Clumpak: a program for identifying clustering modes and packaging population structure inferences across K. Mol Ecol Resour 15:1179-1191. https://doi.org/10.1111/1755-0998.12387

Koskela A, Kaartinen S, Aspi J, Kojola I, Helle P, Rytkönen S (2013) Does Grey Wolf Presence Affect Habitat Selection of Wolverines? Ann Zool Fennici 50:216-224. https://doi. org/10.5735/085.050.0405

Kumar S, Stecher G, Tamura K (2016) MEGA7: Molecular Evolutionary Genetics Analysis Version 7.0 for Bigger Datasets. Mol Biol Evol 33:1870-1874. https://doi.org/10.1093/molbev/msw054

Kyle CJ, Strobeck C (2001) Genetic structure of North American wolverine (Gulo gulo) populations. Mol Ecol 10:337-347. https:// doi.org/10.1046/j.1365-294X.2001.01222.x

Kyle CJ, Strobeck C (2002) Connectivity of Peripheral and Core Populations of North American Wolverines. J Mammal 83:1141-1150. https://doi.org/10.1644/15451542(2002)083<1141:COPACP > 2.0.CO;2

Lamb CT, Ford AT, Proctor MF, Royle JA, Mowat G, Boutin S (2019) Genetic tagging in the Anthropocene: scaling ecology from alleles to ecosystems. Ecol Appl 29:1-17. https://doi. org/10.1002/eap.1876

Landa A, Lindén M, Kojola I (2000) Action plan for the conservation of wolverines (Gulo gulo) in Europe. Council of Europe:1-45

Li YL, Liu JX (2018) StructureSelector: A web based software to select and visualize the optimal number of clusters using multiple methods. Mol Ecol Resour 18:176-177. https://doi. org/10.1111/1755-0998.12719

Librado P, Rozas J (2009) DnaSP v5: a software for comprehensive analysis of DNA polymorphism data. Bioinformatics 25:14511452. https://doi.org/10.1093/bioinformatics/btp187

Lindén H, Danilov PI, Gromtsev AN, Helle P, Ivanter EV, Kurhinen J (2000) Large-scale forest corridors to connect the taiga fauna to Fennoscandia. Wildl Biol 6:179-188. https://doi. org/10.2981/wlb.2000.007

Loiselle BA, Sork VL, Nason J, Graham C (1995) Spatial Genetic Structure of a Tropical Understory Shrub, Psychotria officinalis (Rubiaceae). Am J Bot 82:1420-1425

Luikart G, Ryman N, Tallmon DA, Schwartz MK, Allendorf FW (2010) Estimation of census and effective population sizes: the increasing usefulness of DNA-based approaches. Conserv Genet 11:355-373. https://doi.org/10.1007/s10592-010-0050-7

Magoun AJ, Long CD, Schwartz MK, Pilgrim KL, Lowell RE, Valkenburg P (2011) Integrating motion-detection cameras and hair snags for wolverine identification. J Wildl Manag 75:731-739. https://doi.org/10.1002/jwmg.107

Magoun AJ, Robards M, Packila ML, Glass TW (2017) Detecting Snow at the Den-Site Scale in Wolverine Denning Habitat. Wildl Soc Bull 41:381-387. https://doi.org/10.1002/wsb.765

Malyarchuk BA, Derenko MV, Denisova GA (2015) Mitochondrial genome variability in the wolverine (Gulo gulo). Russ J Genet 51:1113-1118. https://doi.org/10.1134/S1022795415090069

Mantel N (1967) The detection of disease clustering and a generalized regression approach. Cancer Res 27:209-220

May R, Landa A, van Dijk J, Linnell JDC, Andersen R (2006) Impact of infrastructure on habitat selection of wolverines Gulo gulo. Wildl Biol 12:285-295. https://doi.org/IOIOHS]2.0.CO;2

May R, van Dijk J, Landa A, Andersen R, Andersen R (2010) Spatiotemporal ranging behaviour and its relevance to foraging strategies in wide-ranging wolverines. Ecol Model 221:936-943. https://doi.org/10.1016/j.ecolmodel.2009.12.024

May R, Gorini L, van Dijk J, Brøseth H, Linnell JDC, Landa A (2012) Habitat characteristics associated with wolverine den sites in Norwegian multiple-use landscapes. J Zool 287:195204. https://doi.org/10.1111/j.1469-7998.2012.00907.x

McKelvey KS, Copeland JP, Schwartz MK, Littell JS, Aubry KB, Squires JR, Parks SA, Elsner MM, Mauger GS (2011) Climate change predicted to shift wolverine distributions, connectivity, and dispersal corridors. Ecol Appl 21:2882-2897. https://doi. org/10.1890/10-2206.1

McMillan LF, Fewster RM (2017) Visualizations for genetic assignment analyses using the saddlepoint approximation method. Biometrics 73:1029-1041. https://doi.org/10.1111/biom.12667

McRae BH (2006) Isolation by resistance. Evolution 60:1551-1561. https://doi.org/10.1111/j.0014-3820.2006.tb00500.x

Mowry RA, Schneider TM, Latch EK, Gompper ME, Beringer J, Eggert LS (2015) Genetics and the successful reintroduction of the Missouri river otter. Anim Conserv 18:196-206. https ://doi.org/10.1111/acv.12159

Mykrä S, Pohja-Mykrä M (2015) Back-Calculation of Large Carnivore Populations in Finland in 1865-1915. Ann Zool Fenn 52:285300. https://doi.org/10.5735/086.052.0504

Natural Resources Institute Finland (2018) Riistahavainnot.fi. http:// riistahavainnot.fi/suurpedot/suurpetotutkimus/havaintokartat. Accessed 29 Jan 2019

Nei M, Tajima F (1981) Genetic drift and estimation of effective population size. Genetics 98:625-640

Nei M, Maruyama T, Chakraborty R (1975) The bottleneck effect and genetic variability in populations. Evolution 29:1-10. https://doi. org/10.1111/j.1558-5646.1975.tb00807.x

Nomura T (2008) Estimation of effective number of breeders from molecular coancestry of single cohort sample. Evol Appl 1:462474. https://doi.org/10.1111/j.1752-4571.2008.00015.x

Paetkau D, Slade R, Burden M, Estoup A (2004) Genetic assignment methods for the direct, real-time estimation of migration rate: a simulation-based exploration of accuracy and power. Mol Ecol 13:55-65. https://doi.org/10.1046/j.1365-294X.2004.02008.x

Peakall R, Smouse PE (2012) GenAlEx 6.5: genetic analysis in Excel. Population genetic software for teaching and research-an update. Bioinformatics 28:2537-2539. https://doi.org/10.1093/bioin formatics/bts 460

Persson J, Brøseth H (2011) Järv i Skandinavien - status och utbredning 1996-2010 (Wolverines in Scandinavia - status and distribution 1996-2010) [in Swedish with English abstract]. NINA Rapport 732. Norwegian Institute for Nature Research

Persson J, Wedholm P, Segerström P (2010) Space use and territoriality of wolverines (Gulo gulo) in northern Scandinavia. Eur J Wildl Res 56:49-57. https://doi.org/10.1007/s10344-009-0290-3

Pigneur LM, Caublot G, Fournier-Chambrillon C, Fournier P, GiraldaCarrera G, Grémillet X, Le Roux B, Marc D, Simonnet F, Smitz N, Sourp E, Steinmetz J, Urra-Maya F, Michaux JR (2019) Current genetic admixture between relictual populations might enhance the recovery of an elusive carnivore. Conserv Genet 20:1133-1148. https://doi.org/10.1007/s10592-019-01199-9

Piry S, Luikart G, Cornuet J-M (1999) BOTTLENECK: a computer program for detecting recent reductions in the effective size using allele frequency data. J Hered 90:502-503. https://doi. org/10.1093/jhered/90.4.502

Piry S, Alapetite A, Cornuet J-M, Paetkau D, Baudouin L, Estoup A (2004) GENECLASS2: A Software for Genetic Assignment and First-Generation Migrant Detection. J Hered 95:536-539. https ://doi.org/10.1093/jhered/esh074

Pohja-Mykrä M, Kurki S (2008) Asialistalla ahma (Wolverine Management and Public Attitudes in Finland) [in Finnish with English abstract]. Ruralia-Institute, Seinäjoki

Pollak E (1983) A new method for estimating the effective population size from allele frequency changes. Genetics 104:531-548

Prentice MB, Bowman J, Khidas K, Koen EL, Row JR, Murray DL, Wilson PJ (2017) Selection and drift influence genetic 
differentiation of insular Canada lynx (Lynx canadensis) on Newfoundland and Cape Breton Island. Ecol Evol 7:3281-3294. https ://doi.org/10.1002/ece3.2945

Pritchard JK, Stephens M, Donnelly P (2000) Inference of population structure using multilocus genotype data. Genetics 155:945-959

Prugh LR, Stoner CJ, Epps CW, Bean WT, Ripple WJ, Laliberte AS, Brashares JS (2009) The Rise of the Mesopredator, BioScience 59:779-791. https://doi.org/10.1525/bio.2009.59.9.9

Puckett EE, Kristensen TV, Wilton CM, Lyda SB, Noyce KV, Holahan PM, Leslie DM, Beringer J, Belant JL, White D, Eggert LS (2014) Influence of drift and admixture on population structure of American black bears (Ursus americanus) in the Central Interior Highlands, USA, 50 years after translocation. Mol Ecol 23:2414-2427. https://doi.org/10.1111/mec.12748

Puechmaille SJ (2016) The program structure does not reliably recover the correct population structure when sampling is uneven: subsampling and new estimators alleviate the problem. Mol Ecol Resour 16:608-627. https://doi. org/10.1111/1755-0998.12512

Pulliainen E (1968) Breeding biology of the wolverine (Gulo gulo L.) in Finland. Ann Zool Fenn 5:338-344

Pulliainen E (1982) Experiences in the protection of the large predators in Finland. Int J Stud Anim Prob 3:33-41

Pulliainen E (1990) Recolonization of Finland by the brown bear in the 1970s and 1980s. Aquilo Ser Zool 27:21-25

Pulliainen E, Nyström V (1974) Suomen suurpedot. Tammi, Helsinki

QGIS Development Team (2018) QGIS Geographic Information System. Open Source Geospatial Foundation Project. http:// qgis.osgeo.org

R Core Team (2017) R: A language and environment for statistical computing. R Foundation for Statistical Computing, Vienna

Rannala B, Mountain JL (1997) Detecting immigration by using multilocus genotypes. PNAS 94:9197-9201

Rauset GR, Low M, Persson J (2015) Reproductive patterns result from age-related sensitivity to resources and reproductive costs in a mammalian carnivore. Ecology 96:3153-3164. https://doi. org/10.1890/15-0262.1

Rico Y, Morris-Pocock J, Zigouris J, Nocera JJ, Kyle CJ (2015) Lack of spatial immunogenetic structure among wolverine (Gulo gulo) populations suggestive of broad scale balancing selection. PLoS One 10(10):e0140170. https://doi.org/10.1371/ journal.pone.0140170

Ripple WJ, Estes JA, Beschta RL, Wilmers CC, Ritchie EG, Hebblewhite M, Berger J, Elmhagen B, Letnic M, Nelson MP, Schmitz OJ, Smith DW, Wallach AD, Wirsing AJ (2014) Status and ecological effects of the world's largest carnivores. Science 343:151-163. https://doi.org/10.1126/science.1241484

Rousset F (2008) genepop'007: a complete re-implementation of the genepop software for Windows and Linux. Mol Ecol Resour 8:103-106. https://doi.org/10.1111/j.1471-8286.2007.01931.x

Ruiz-González A, Madeira MJ, Randi E, Abramov AV, Davoli F, Gómez-Moliner BJ (2013) Phylogeography of the forest-dwelling European pine marten (Martes martes): new insights into cryptic northern glacial refugia. Biol J Linn Soc 109:1-18. https://doi.org/10.1111/bij.12046

Schwartz MK, Aubry KB, McKelvey KS, Pilgrim KL, Copeland JP, Squires JR, Inman RM, Wisely SM, Ruggiero LF (2007) Inferring geographic isolation of wolverines in California using historical DNA. J Wildl Manag 71:2170-2179

Schregel J, Kopatz A, Hagen SB, Brøseth H, Smith ME, Wikan S, Wartiainen I, Aspholm PE, Aspi J, Swenson JE, Makarova O, Polikarpova N, Schneider M, Knappskog PM, Ruokonen M, Kojola I, Tirronen KF, Danilov PI, Eiken HG (2012) Limited gene flow among brown bear populations in far Northern Europe? Genetic analysis of the east-west border population in the Pasvik Valley. Mol Ecol 21:3474-3488
Silva P, López-Bao JV, Llaneza L, Álvares F, Lopes S, Blanco JC, Cortés Y, García E, Palacios V, Rio-Maior H, Ferrand N, Godinho R (2018) Cryptic population structure reveals low dispersal in Iberian wolves. Sci Rep 8:14108. https://doi.org/10.1038/ s41598-018-32369-3

Slatkin M (2008) Linkage disequilibrium-understanding the evolutionary past and mapping the medical future. Nat Rev Genet 9:477-485. https://doi.org/10.1038/nrg2361

Sommer R, Benecke N (2004) Late- and Post-Glacial history of the Mustelidae in Europe. Mammal Rev 34:249-284. https://doi. org/10.1111/j.1365-2907.2004.00043.x

Tammeleht E, Remm J, Korsten M, Davidson J, Tumanov I, Saveljev A, Männil P, Kojola I, Saarma U (2010) Genetic structure in large, continuous mammal populations: the example of brown bears in northwestern Europe. Mol Ecol 19:5359-5370. https ://doi.org/10.1111/j.1365-294X.2010.04885.x

Thompson JD, Higgins DG, Gibson TJ (1994) CLUSTAL W: improving the sensitivity of progressive multiple sequence alignment through sequence weighting, position-specific gap penalties and weight matrix choice. Nucleic Acids Res 22:4673-4680

Tomasik E, Cook JA (2005) Mitochondrial Phylogeography and Conservation Genetics of Wolverine (Gulo gulo) of Northwestern North America. J Mammal 86:386-396. https://doi. org/10.1644/BER-121.1

Tucker JM, Schwartz MK, Truex RL, Wisely SM, Allendorf FW (2014) Sampling affects the detection of genetic subdivision and conservation implications for fisher in the Sierra Nevada. Conserv Genet 15:123-136. https://doi.org/10.1007/s1059 2-013-0525-4

Vähä J, Erkinaro J, Niemelä E, Primmer CR (2007) Life-history and habitat features influence the within-river genetic structure of Atlantic salmon. Mol Ecol 16:2638-2654. https://doi. org/10.1111/j.1365-294X.2007.03329.x

Valtonen M, Palo JU, Aspi J, Ruokonen M, Kunnasranta M, Nyman $\mathrm{T}$ (2014) Causes and consequences of fine-scale population structure in a critically endangered freshwater seal. BMC Ecol 14:22. https://doi.org/10.1186/1472-6785-14-22

Van Oosterhout C, Hutchinson WF, Wills DPM, Shipley P (2004) micro-checker: software for identifying and correcting genotyping errors in microsatellite data. Mol Ecol Notes 4:535-538. https://doi.org/10.1111/j.1471-8286.2004.00684.x

Vangen KM, Persson J, Landa A, Andersen R, Segerström P (2001) Characteristics of dispersal in wolverines. Can J Zool 79:16411649. https://doi.org/10.1139/z01-124

Vucetich JA, Waite TA (2003) Spatial patterns of demography and genetic processes across the species' range: Null hypotheses for landscape conservation genetics. Conserv Genet 4:639645. https://doi.org/10.1023/A:1025671831349

Wahlund S (1928) Zusammensetzung von Populationen und Korrelationserscheinungen vom Standpunkt der Vererbungslehre aus betrachtet. Hereditas 11:65-106

Waits LP, Luikart G, Taberlet P (2001) Estimating the probability of identity among genotypes in natural populations: cautions and guidelines. Mol Ecol 10:249-256. https://doi.org/10.1046/ j.1365-294X.2001.01185.x

Walker CW, Vilà C, Landa A, Lindén M, Ellegren H (2001) Genetic variation and population structure in Scandinavian wolverine (Gulo gulo) populations. Mol Ecol 10:53-63. https://doi. org/10.1046/j.1365-294X.2001.01184.x

Wallén J, Statham MJ, Ågren E, Isomursu M, Flagstad Ø, BjørneboeBerg T, Sacks BN, Norén K (2018) Multiple recolonization routes towards the north: population history of the Fennoscandian red fox (Vulpes vulpes). Biol J Linn Soc 124:621-632. https://doi.org/10.1093/biolinnean/bly060

Wang J, Santiago E, Caballero A (2016) Prediction and estimation of effective population size. Heredity 117:193-206 
Waples RS (2006) A bias correction for estimates of effective population size based on linkage disequilibrium at unlinked gene loci*. Conserv Genet 7:167. https://doi.org/10.1007/s1059 2-005-9100-y

Waples RS, Do C (2010) Linkage disequilibrium estimates of contemporary $\mathrm{Ne}$ using highly variable genetic markers: a largely untapped resource for applied conservation and evolution. Evol Appl 3:244-262. https://doi.org/10.111 1/j.1752-4571.2009.00104.x

Wilson GM, Van Den Bussche RA, Kennedy PK, Gunn A, Poole K (2000) Genetic variability of wolverines (Gulo gulo) from the Northwest Territories, Canada: conservation implications. J Mammal 36:186-196. https://doi.org/10.1644/15451542(2000)081<0186:GVOWGG > 2.0.CO;2

Wisely SM, McDonald DB, Buskirk SW (2003) Evaluation of the genetic management of the endangered black-footed ferret (Mustela nigripes). Zoo Biol 22:287-298. https://doi. org/10.1002/zoo.10089
Wright S (1943) Isolation by Distance. Genetics 28:114-138

Zigouris J, Dawson N, Bowman J, Gillett RM, Schaefer JA, Kyle CJ (2012) Genetic isolation of wolverine (Gulo gulo) populations at the eastern periphery of their North American distribution. Conserv Genet 13:1543-1599. https://doi.org/10.1007/s1059 2-012-0399-x

Zigouris J, Schaefer JA, Fortin C, Kyle CJ (2013) Phylogeography and Post-Glacial Recolonization in Wolverines (Gulo gulo) from across Their Circumpolar Distribution. PLoS ONE 8(12):e83837. https://doi.org/10.1371/journal.pone.0083837

Publisher's Note Springer Nature remains neutral with regard to jurisdictional claims in published maps and institutional affiliations. 